ASSESSING PERCEPTIONS OF PARENTS' COMMUNICATION ACCOMMODATION IN

RELATION TO SEXUAL AND GENDER MINORITY ADULT CHIDLREN'S CHILD-

PARENT COMMUNICATION APPREHENSION AND MENTAL HEALTH

A Dissertation

presented to

the Faculty of the Graduate School

at the University of Missouri-Columbia

In Partial Fulfillment

of the Requirements for the Degree

Doctor of Philosophy

by

MARIA BUTAUSKI

Dr. Haley Kranstuber Horstman, Dissertation Supervisor

MAY 2019 
The undersigned, appointed by the dean of the Graduate School, have examined the dissertation entitled:

\section{ASSESSING PERCEPTIONS OF PARENTS' COMMUNICATION ACCOMMODATION IN RELATION TO SEXUAL AND GENDER MINORITY ADULT CHIDLREN'S CHILD- PARENT COMMUNICATION APPREHENSION AND MENTAL HEALTH}

Presented by Maria Butauski, a candidate for the degree of doctor of philosophy, and hereby certify that, in their opinion, it is worthy of acceptance.

Professor Haley Kranstuber Horstman

Professor Colleen Colaner

Professor Brian Houston

Professor Wayne Brekhus 


\section{DEDICATION}

I dedicate this dissertation to the people who have supported me the most and to my loving pup and writing companion, Zimmer.

To my wonderful partner, Abi, I dedicate this work to you for helping me stay grounded. Thank you for your patience, encouragement, and support. Thank you for all the laughs, adventures, and delicious home-cooked meals. I cannot imagine getting through the long hours of coursework, studying, writing, job applications, and all that graduate school and life entails without you by my side. I love you.

To my dad, I dedicate this work to you because without your support, I would not be where I am today. Thank you for encouraging me to chase my dreams and instilling me with a strong work ethic. Most of all, thank you for your unconditional love and support. I am so proud of how far our relationship has come since I first came out to you seven years ago.

To two of my dearest friends, Alex and Angela, I dedicate this work to you because our group chat, which has been going strong since we finished our master's program, has been my saving grace many times over the last four years. Thank you both for reminding me that I belonged in my doctoral program and that I would succeed. Most of all, thank you for always being there for me and for being such great friends.

To my officemates and fellow strong, empowered women, Sarah and Anna, I dedicate this work to you as because you inspire me. Thank you for your words of motivation along the way and for being such thoughtful friends and colleagues. \#TheFutureIsSwitzler106!

To my cohort (Josh, Sarah, Anna, Joel, Alyssa - and Sopheak and Kristin!), I dedicate this work to you for all the laughs, support, and commiseration. It's been a wild ride.

Finally, to my advisor, Haley Horstman, I dedicate this work to you for all the guidance and encouragement you provided along the way. Thank you for all the celebratory GIFs and words of encouragement. I could not have done this without you. 


\section{ACKNOWLEDGMENTS}

First and foremost, I want to thank my advisor, Dr. Haley Horstman. Words cannot adequately describe how grateful I am to have had such an amazing advisor these past four years. I greatly appreciate Haley's thoughtful and constructive mentorship in research and teaching. I have learned so much from her. She spent countless hours providing me with feedback on my writing, meeting with me to discuss my research, and writing letters of recommendation on my behalf. This work would not have been possible without Haley.

I also want to Drs. Mei-Chen Lin and Jeffrey Child for your mentorship during my master's program and for helping me matriculate into a doctoral program. With their guidance and encouragement, I earned a spot in my first-choice doctoral program. I am so grateful for their mentorship and support.

I also want to thank all the faculty of the Department of Communication at the University of Missouri. Whether I have taken a class with you or worked with you directly, I have learned from each of you. I want to specially thank Dr. Ben Warner for his excellent teaching and making statistics less scary. Without Ben, there is no way I would have been able to use structural equation modeling in my dissertation. I want to thank Dr. Brian Houston for giving me the opportunity to work with and learn from him and conduct important resilience-focused research. I also want to thank Dr. Colleen Colaner for being an excellent professor and mentor. I have gained so much perspective on family communication and research from Colleen and I am so grateful to have had the opportunity to learn and work with her.

Finally, thank you to all my dissertation committee members. Thank you for helping me reach this milestone. 


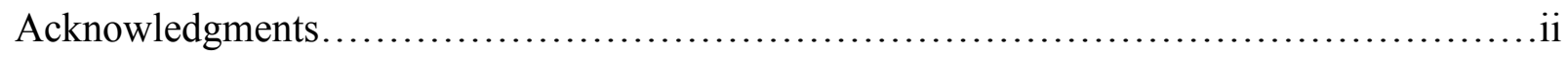

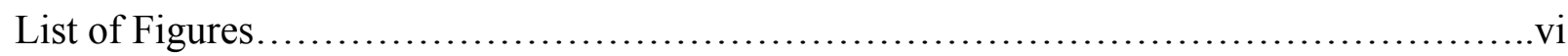

List of Tables..................................................................

Abstract...........................................................................

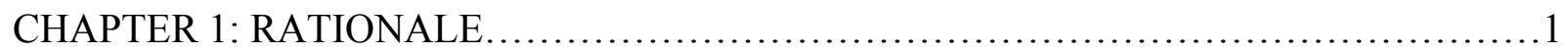

Gender and Sexual Minority Individuals and Mental Health Challenges................

SGM individuals' mental health and resilience after coming out to parents.......2

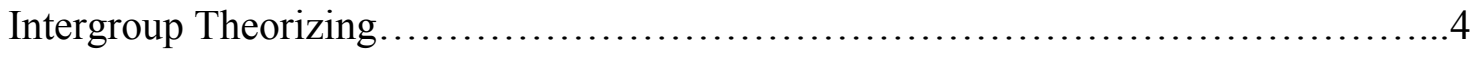

Communication Accommodation Theory.............................. 6

Goals and Contributions of the Current Dissertation.......................... 9

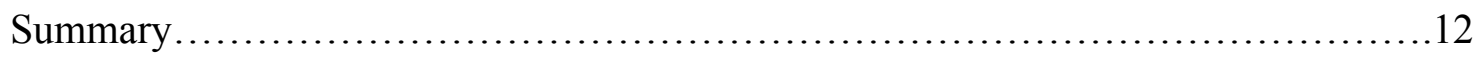

CHAPTER 2: REVIEW OF LITERATURE..................................... 12

The Intergroup Nature of SGM Adult Children's Parent-child Relationships.......... 13

Intergroup Communication: Parents' Reactions to their Child's Coming Out...14

Communication Accommodation Theory............................. 16

Parents' Accommodative Communication with SGM Adult Children..................19

Respect for Divergent Values and SGM Adult Children's Mental Health.......20

SGM Identity Support and SGM Adult Children's Mental Health.............22

Communication Accommodation and CPCA............................ 24

CPCA and SGM Adult Children's Mental Health......................... 27

CHAPTER 3: METHODS ..................................................... 31

Recruitment Procedures.................................................. 31 
Participants.

Procedures.....................................................................

Preliminary Analysis.................................................... 34

Measurement Model Analysis............................................... 35

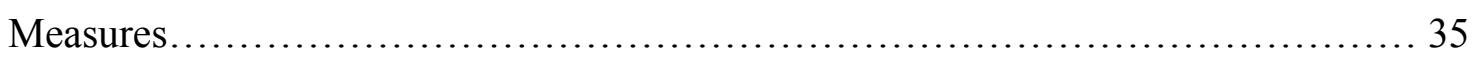

Parents' respect for divergent values................................ 35

Parents' SGM identity support................................... 36

Child-parent communication apprehension............................ 37

Depression................................................... 37

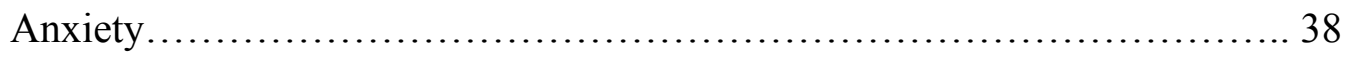

Structural Model Analysis.................................................. 38

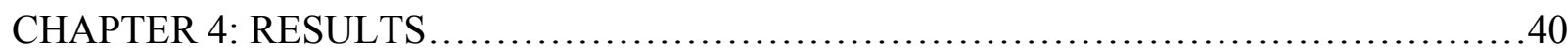

Preliminary Analyses................................................... 40

Hypothesis Testing .................................................. 40

CHAPTER 5: DISCUSSION .............................................. 43

The Positive Role of Parents' Communication Accommodation....................44

Future directions: Intergroup parent-child relationships.................... 50

Communication Apprehension in Close Intergroup Relationships................. 53

Parent-child Communication and SGM Adult Children's Mental Health...............56

Future directions: Fostering resilience.................................60

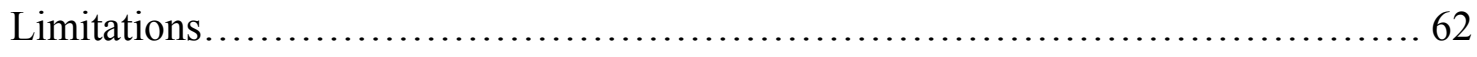

Practical Applications..................................................... 64

Conclusion............................................................ 64 


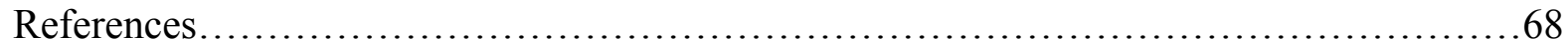

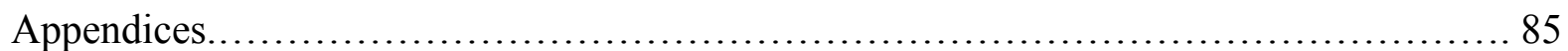

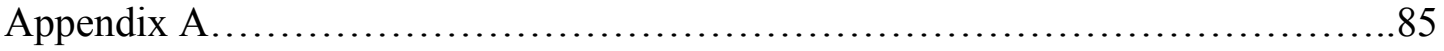

Appendix B................................................................. 86

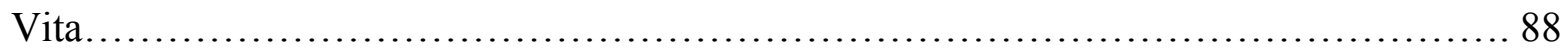




\section{LIST OF FIGURES}

Figure 1: Hypothesized Structural Model..............................................29

Figure 2: Tested Structural Model..............................................42 


\section{LIST OF TABLES}

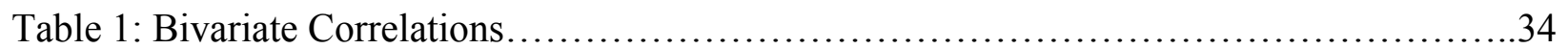

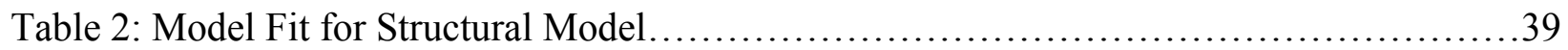

Table 3: Structural Equation Modeling Results with Standardized Coefficients.................42 


\begin{abstract}
Sexual and gender minority (SGM) individuals, or people who identify as lesbian, gay, bisexual, transgender, genderqueer, nonbinary, or any other self-identified sexual orientation or gender identity, deal with chronic minority stress, which is associated with negative mental health outcomes such as depression, anxiety, and suicidal ideation (Medley et al., 2016; Meyer, 2003). Part of the chronic minority stressed faced by this population stems from a lack of support in their parent-child relationships (Heatherington \& Lavner, 2008; Savin-Williams, 2001, 2005). The present dissertation brought attention to the inherently intergroup nature of SGM offspring's parent-child relationships by examining how SGM adult children's parent-child communication relates to their mental health, assessed by their rates of depression and anxiety, respectively. Guided by intergroup theorizing and communication accommodation theory, the present study investigated how SGM adult children's perceptions of their parents' accommodative communication behaviors - respect for divergent values and SGM identity support - related to SGM adult children's experiences of child-parent communication apprehension (CPCA), and in turn, their mental health. Parents' accommodative communication promoted more supportive, open communication environments characterized by lower levels of CPCA, which in turn promoted more positive mental health outcomes. Results demonstrated that higher levels of CPCA were associated with higher rates of depression among SGM adult children. Results highlighted the importance of respect for divergent values and identity support in creating healthy communication environments in close intergroup family relationships and fostering individual mental health outcomes. Findings shed light on how SGM adult children's parentchild communication relates to their mental health and contribute to a growing body of research examining close intergroup family relationships.
\end{abstract}




\section{CHAPTER 1: RATIONALE}

\section{Gender and Sexual Minority Individuals and Mental Health Challenges}

Sexual and gender minority (SGM) individuals - or those who identify as lesbian, gay, bisexual, transgender, genderqueer, nonbinary, or any other self-identified sexual orientation or gender identity - face minority stress or unique challenges within the pervasive heteronormative culture that are associated with poor mental health outcomes (Meyer, 2003). Minority stress theory asserts that SGM people experience chronic stress from discrimination, stigma, and prejudice present in heterosexist societies (Meyer, 1995, 2003; Woodford, Paceley, Kulick, \& Hong, 2015). Minority stress stems from a variety of unique challenges faced by this community, including a lack of family support, family rejection (Asakura, 2016; Bariola et al., 2015; Ryan, Russel, Huebner, Diaz, \& Sanchez, 2010), identity management (i.e., revealing or concealing SGM identity across situations) (Asakura, 2016; Sanlo, 2004), and discrimination, incivility, and harassment (Grossman \& D’Augelli, 2006; Woodford, Han, Craig, Lim, \& Matney, 2014). SGM individuals' experiences of stigma, prejudice, and discrimination ultimately may create chronic minority stress (Meyer, 2003).

Chronic minority stress is associated with poor mental health, such as lower levels of self-esteem and feelings of alienation (Evans \& D'Augelli, 1996), substance abuse, and even suicide (Ryan et al., 2010; Woodford, Paceley, Kulick, \& Hong, 2015). The Substance Abuse and Mental Health Services Administration (SAMHSA) found that lesbian, gay, and bisexual adults were more likely to use illicit drugs, smoke cigarettes, have substance use disorders, need substance use treatment, and experience mental illness compared to their heterosexual counterparts (Medley et al., 2016). Additionally, one in every five people with sexual minority identities attempt suicide in their lifetime (Salway Hottes, Bogaert, Rhodes, Brennan \& Gesink, 
2016). Forty percent of gender minorities attempt suicide and of those 40 percent, 92 percent attempt suicide by age 25 (James, Herman, Rankin, Keisling, Mottet, \& Anafi, 2016).

Part of the chronic stress faced by SGM individuals stems from identity management, which often revolves around coming out (Asakura, 2016; Sanlo, 2004), or the processes involved with disclosing an SGM identity (Savin-Williams, 2001). Coming out often involves navigating unsupportive relationships and social environments beyond initial disclosures of one's SGM identity (Meyer, 2003). Coming out to one's family, especially parents, is often considered the most stressful, anxiety-inducing coming out experiences (Savin-Williams 2001, 2005). Familial rejections of or resistance to SGM identities are one of the most significant stressors for SGM individuals (Szymanski \& Gupta, 2009; Willoughby, Malik, \& Lindahl, 2006; Willoughby, Doty, \& Malik, 2010).

SGM individuals' mental health and resilience after coming out to parents. Coming out to parents has serious mental health implications for SGM individuals (Ryan, Huebner, Diaz, \& Sanchez, 2009; Willoughby et al., 2006). SGM young adults with experiences of memorable rejections from family are at a higher risk for suicide, depression, and substance abuse (Ryan, Huebner, Diza, \& Sanchez, 2009). Parental rejection and unsupportive parental relationships after coming out often damages SGM children's concepts of self (Savin-Williams, 1989). Lacking support from parents is often associated with negative mental and behavioral outcomes for SGM individuals (e.g., depression, risky behavior) (Ryan et al., 2009; Willoughby et al., 2006).

On the other hand, parent-child relationships can be essential in cultivating resilience (Theiss, 2018) and reliable, supportive parents may serve as an invaluable protective factor fostering resilience among SGM individuals (Mena \& Vaccaro, 2013; Ryan et al., 2009). 
Resilience refers to one's ability to effectively cope with adversity (Afifi, 2018) and is a powerful factor contributing to the mental health and overall well-being of SGM individuals (Asakura, 2016; Colpitts \& Gahagan, 2016; McElroy, Wintemberg, Cronk, \& Everett, 2016; Singh, 2013). Affirming and supportive relationships, such as parent-child relationships, contribute to resilience, positive mental health outcomes (Kwon, 2013; Mena \& Vaccaro, 2013; Ryan et al., 2010), and positive perceptions of self (Savin-Williams, 1989) in SGM individuals. In other words, parents who are supportive and affirming of their children's SGM identity help ignite positive reflected appraisals that foster more positive perceptions of self and mental health outcomes for their children (Kwon, 2013; Savin-Williams, 1989).

Parental support upon and beyond a child's coming out highlights parents' resilience and can contribute to SGM individuals' resilience and well-being (Asakura, 2016; Mena \& Vaccaro, 2013). The ways parents adjust to their child's coming out often reflect parents' resilience and commitment to supporting their child (Butauski \& Horstman, 2018; Gonzalez, Rostosky, Oggle, \& Riggle, 2013). Parents' direct acknowledgement of their concerns for their child based on their SGM identity (i.e., bullying, discrimination) and explicit efforts to learn how to best support their child reflect parents' resilience (Butauski \& Horstman, 2018). Overall, these positive adaptations to and support of their children's coming out positively contributes to SGM children's senses of self and resilience (Savin-Williams, 1989; Ryan et al., 2010).

Although researchers emphasize the importance of parents' support of their child's SGM identity upon their initial coming out (Heatherington \& Lavner, 2008; Ryan et al., 2009; SavinWilliams, 1989), it is likely that the nature of parent-child communication beyond the initial coming out event is fundamental to SGM offspring's well-being. Many parents take time to positively adjust to their child's coming out and overcome their negative feelings towards SGM 
individuals (Baptist \& Allen, 2008; Gonzalez et al., 2013; Grafsky, 2014). This often involves questioning deeply ingrained values they hold towards sexuality and gender (Gonzalez et al, 2013). Because parent-child relationship need time to adjust to a child's coming out, it is essential to gain a deeper understanding of what parent-child relationships beyond a child's initial coming out.

In sum, supportive, affirming parent-child relationships are central to SGM offspring's well-being (Ryan et al., 2010). However, after the initial coming out event, SGM individuals may be navigating precarious parent-child relationships that leave them feeling distressed and uneasy toward communication with their parents. Some of the uneasiness of parent-child relationships after coming out may be due to differences in their values, attitudes, and beliefs, particularly toward SGM individuals and issues. Thus, in the present study, I investigate the intergroup dynamics at play in parent-adult SGM children relationships.

\section{Intergroup Theorizing}

Although many parents describe experiencing personal transformations when learning more about and growing to embrace their child's SGM identity (Gonzalez et al., 2013), some parents have difficulty understanding and accepting their child's SGM identity (Savin-Williams, 2001). Parents' difficulty in understanding and accepting their child's SGM identity often stems from deeply-held religious and traditional family values (Baiocco et al. 2015; Baptist \& Allen, 2008; Gonzalez et al., 2013; Newman \& Muzzonigro, 1993). Similarly, older generations tend to have more difficulty positively adjusting to a family member's coming out (Dunlap, 2014; Savin-Williams, 2008). These findings suggest that SGM individuals' relationships with their parents might be characterized by unique intergroup dynamics that play a central role in how parents react to their initial coming out and persists afterwards. 
Intergroup theorizing recognizes the central role of social identities in communication such that it posits that interactions are influenced by the group memberships of all parties involved, even between parties with a common group identity, such as a family (Soliz, 2007; Soliz \& Rittenour, 2012). Thus, communication varies based on both interpersonal and intergroup salience (Harwood, Raman, \& Palomares, 2006). SGM adult children's parent-child communication may be characterized by high or low levels of interpersonal salience and high or low levels of intergroup salience. For example, SGM adult children with strong relational histories with their parents may or may not experience high levels of intergroup salience in their parent-child relationships. Situations in which (heterosexual and cisgender) parents support their child's SGM identity are likely characterized by low levels of intergroup salience based on the child's SGM identity. On the other hand, when parents have strong negative reactions to their child's SGM identity, they likely have parent-child relationships characterized by high levels of intergroup salience.

Coming out to one's parents likely brings intergroup salience to the forefront of the parent-child relationship as many parents need time to adjust to and be supportive of their child's SGM identity, regardless of their religious beliefs (Butauski \& Horstman, 2018; Grafsky, 2014; Tyler, 2015). Many parents initially react negatively to their child's coming out and/or need time to adjust to their child's SGM identity (Gonzalez et al., 2013; Grafsky, 2014), but most parentchild relationships recalibrate or even strengthen post-coming out (Savin-Williams, 2005).

Taken together, these findings show how intergroup dynamics play a role in SGM offspring's relationships with their parents. Any recalibration and strengthening of parent-child relationships post-coming out is likely fostered by accommodative parental communication, or communication that acknowledges and conveys regard for their child's SGM identity and 
subsequent values. As such, the current study calls upon communication accommodation theory (CAT) to explore intergroup dynamics in SGM adult children's parent-child relationships by assessing SGM adult children's perceptions of their parents' SGM identity support and respect for divergent values as accommodative communication behaviors and SGM adult children's child-parent communication apprehension (CPCA) as they relate to SGM offspring's depression and anxiety.

Communication accommodation theory. CAT guides researchers' understanding of communication behaviors based on intergroup characteristics and focuses on the extent to which communication serves as mechanism to enhance, diminish, or maintain intergroup salience (Giles \& Soliz, 2015; Harwood et al., 2006). In other words, the degree to which one's communication is accommodating during an intergroup interaction can help increase interpersonal connection or maintain or amplify intergroup salience between parties. Accommodative communication behaviors show acknowledgement and respect for others' interpersonal and intergroup characteristics (Gallois et al., 2005; Harwood, 2000). Individuals can be accommodating by demonstrating care and concern through supportive communication (Burleson \& MacGeorge, 2002; Soliz, Thorson, \& Rittenour, 2009), conveying respect divergent values (Colaner, Soliz, \& Nelson, 2014), selecting appropriate topics of discussion (Harwood, Soliz, \& Lin, 2006), and exercising other linguistic, paralinguistic, discursive, and nonverbal adaptations (Gallois et al., 2005; Harwood, 2000).

In the current study, the extent to which parents' communication is accommodating is assessed by SGM adult children's perceptions of their parents' SGM identity support - or, behaviors that acknowledge and demonstrate respect and acceptance towards their child's SGM identity - and respect for divergent values - or behaviors that acknowledge and demonstrate 
respect and acceptance towards values SGM adult children hold that may be divergent from their parents. Parents' SGM identity support is central to SGM children's abilities to form positive perceptions of self (Savin-Williams, 1989). SGM individuals with parents who support their SGM identity likely feel more comfortable openly communicating with their parents and likely have better mental health. SGM identity-specific support from parents, and from one's social group at large, is extremely important, but often unavailable (Doty, Willoughby, Lindahl, \& Malik, 2010). As such, parental support is an important protective factor for SGM individuals, given their risk for chronic minority stress (Mena \& Vaccaro, 2013; Rosario et al., 2005). Thus, it is important to understand how perceptions of parents' SGM identity support relates to SGM adult children's mental health outcomes, assessed in the current study by anxiety and depression. Another way parents can help their SGM offspring feel supported is through conveying respect for divergent values. Parents' respect of their child's divergent values illustrates parents' respect for their child's SGM identity and the values that may come along with that identity (Colaner et al., 2014). For example, SGM individuals likely have different values regarding gender and sexuality in comparison to non-SGM individuals (Soliz, Ribarsky, Harrigan, \& TyeWilliams, 2010). Adapting communication to avoid offending, belittling, or disregarding another's beliefs illustrates respect for divergent values (Colaner et al., 2014). Parents' respect for their SGM child's divergent values demonstrates affirmation of the child's identity and belief systems. Feeling respect from others towards one's social identity, such as an SGM identity, can positively predict one's overall well-being and sense of self (DeCremer \& Tyler, 2005; SavinWilliams, 1989).

Parents' accommodative communication behaviors also likely foster a more supportive, open communication environment by decreasing SGM adult children's $C P C A$, or fear and 
anxiety toward actual or anticipated interactions with their parents (Luchetti, Powers, \& Love, 2002). For example, emerging adults who felt their parents supported their career goals and religious and political beliefs were more open in discussing these topics and less motivated to avoid such topics (Butauski, 2018a). Conversely, when emerging adults felt their parents were trying to interfere with (i.e., attempting to challenge or change) their career goals and religious and political beliefs, they were more motivated to avoid these topics to protect themselves and the parent-child relationship (Butauski, 2018a). This suggests they were experiencing CPCA as they were apprehensive towards discussing these topics with their parents. Offspring experiencing CPCA are less likely to share information with their parent (Luchetti et al., 2002) and seek support from their parents (Cascio, Guzzo, Pace, \& Pace, 2013), which can make the parent-child relationship difficult to navigate.

Communication quality in parent-child relationships is consequential to parents, children, and the nature of their family relationships (Fitzpatrick \& Vangelisti, 1995; Maccoby \& Martin, 1983) and CPCA can be distressing and significantly impede the quality of communication between parents and children (Aloia \& Strutzenburg, 2019; Daly, McCroskey, Ayers, Hopf, \& Ayers, 1997; Luchetti et al., 2002). Given the adverse effects of CPCA, experiencing consistently high levels of CPCA may leave SGM offspring less motivated to maintain meaningful relationships with their parents (Butauski, 2018b).

Overall, parents' accommodative communication behaviors may aid in reducing CPCA, which is important because CPCA is characteristic of precarious parent-child relationships that can have negative effects on SGM adult children's well-being (Aloia \& Strutzenburg, 2019; Wright, 2000). Thus, the current study assesses how parents' accommodative communication relates to SGM offspring's CPCA and mental health, assessed by experiences of depression and 
anxiety, respectively. In doing so, I propose that parents' accommodative communication is associated with lower levels of CPCA, which fosters a healthier parent-child relationship, and thus, more positive mental health outcomes for SGM offspring.

\section{Goals and Contributions of the Current Dissertation}

Given the pervasive mental health concerns of the SGM community and the valuable protective role of supportive parent-child relationships (Baiocco et al., 2015; Ryan et al., 2009, Savin-Williams, 1989), it is useful to understand how parents' communication accommodation (or lack thereof) relates to SGM adult children's CPCA, and in turn, SGM adult children's mental health outcomes. SGM individuals who perceive their parents as less supportive of their SGM identity and not respectful of their differences likely experience higher levels of CPCA, which is likely be distressing and, thus, related to higher levels of depression and anxiety. On the other hand, parents' SGM identity support and respect for divergent values likely reduce SGM children's CPCA, which fosters a healthy relationship environment, and thus relates to more positive mental health outcomes. The empirical assessment of these assumptions will provide three practical and theoretical contributions to scholarship concerned with SGM adult children's parent-child relationships and mental health.

First, this study contributes to the growing body of research on SGM offspring's parentchild relationship by examining the relationship from a communication perspective. Although researchers consistently emphasize importance of this relationship, scholars have yet to investigate SGM individuals' parent-child communication and how this relates to their wellbeing. Filling this gap, the current study investigates how communication in the parent-child relationship beyond the initial coming out event relates to SGM adult children's CPCA, and in turn, their mental health outcomes. This study specifically investigates parents' accommodative 
communication conveyed through their respect for divergent values and SGM identity support as they relate to better mental health outcomes and lower levels of CPCA among SGM offspring.

Second, this study builds upon intergroup family communication research (Colaner et al., 2014; Soliz, Ribarsky, Harrigan, \& Tye-Williams, 2010; Soliz \& Rittenour, 2012). Intergroup dynamics are inherent to parent-child relationships in which the child identifies as a GSM identity and the child's parents are heterosexual and cisgender (i.e., identify as the gender they were assigned at birth). Exploring these intergroup parent-child relationships will further enhance the practical application of CAT to important intergroup family relationships (Soliz \& Rittenour, 2012). Along with these distinct social identities there may be distinct differences in values relative to religion, politics, human rights, gender, and sexuality (Butauski, 2018b; Dunlap, 2014; Jenkins, 2008; Rosenfeld et al., 2012). Thus, investigating communication in GSM individuals' relationships with their parents can illuminate how the intergroup dynamics of parent-child communication contribute to GSM offspring's mental health.

Finally, the current study examines important links between parent-child communication and mental health outcomes in a vulnerable population. Given the valuable protective role of supportive parent-child relationships to the heightened vulnerabilities of the GSM community (Baiocco et al., 2015; Ryan et al., 2009), it is imperative to gain an understanding of how parentchild communication associates with important mental health outcomes of GSM offspring. Findings from the current study will contribute to a growing body of research emphasizing the positive role of communication accommodation in family relationships (Colaner et al., 2014; Rittenour \& Soliz, 2009; Soliz, 2007) and highlight how parent-child communication relates to mental health. Exploring how specific parental communication behaviors can enhance or serve as a detriment to their SGM offspring's mental health can provide scholars and practitioners a 
greater understanding of the complexities of navigating these parent-child relationships. For example, parents' communication accommodation can aid in their abilities to surpass intergroup differences (Colaner et al., 2014), create supportive and affirming communication climates, and reduce intergroup anxiety in intergroup family relationships (Soliz et al., 2010).

As such, the current study provides important avenues for future resilience-focused research on the SGM community. SGM individuals' affirming, supportive relationships contribute to their resilience and, thus, are associated with more positive mental health outcomes (Kwon, 2013; Mena \& Vaccaro, 2013; Ryan et al., 2010) and more positive perceptions of self (Savin-Williams, 1989). Research evidences the important of parents' initial support of their child's SGM identity upon their first coming out, however little is known about the role of parents' affirming and supportive communication on SGM offspring's well-being beyond the initial coming out event.

\section{Summary}

In sum, the current study explores the inherently intergroup nature of SGM adult children's parent-child relationships by investigating their perceptions of their parents' accommodative communication behaviors (i.e., respect for divergent values and SGM identity support) in relation to their CPCA and mental health (i.e., depression and anxiety). This research will provide valuable insights to SGM children's parent-child relationship dynamics beyond their initial coming out. The following chapter reviews relevant literature to propose the hypotheses of the current study. 


\section{CHAPTER TWO: REVIEW OF LITERATURE}

\section{The Intergroup Nature of SGM Adult Children's Parent-child Relationships}

The intergroup perspective of communication recognizes how social identities play a role in human interaction, such that interactions will be influenced by the social identities or group memberships present in those interactions (Harwood et al., 2006). Social identities play a role in interactions even if participants do not recognize intergroup characteristics (Harwood et al., 2006). Although intergroup communication often references communication between two separate and distinct social groups (e.g. an SGM individual talking with a cis-gender heterosexual individual), intergroup communication can also occur between individuals sharing a common group identity, such as a shared family identity (Soliz, 2007; Soliz \& Rittenour, 2012). Therefore, Harwood et al. (2006) purport that all communication varies based on levels of both interpersonal and intergroup salience.

Over the lifespan, a variety of factors may bring intergroup salience to the forefront of parent-child relationships. In general, parent-child relationships characterized by relational closeness and open communication likely have high levels of interpersonal salience, whereas parent-child relationships characterized by less relational closeness and less communication openness likely have lower levels of interpersonal salience. In adolescence and emerging adulthood, intergroup salience may become more prevalent as offspring challenge the hierarchical nature of the parent-child relationship by emphasizing their autonomy from their parents (Butauski, 2018; Petronio, 2002). One way adolescents and emerging adults do this is by erecting thicker privacy boundaries, or communicating less openly with their parents (Butauski, 2018; Dietvorst, Hiemstra, Hillegers, \& Keijsers, 2017; Petronio, 2002). As emerging adults transition to young adulthood, the need to exude autonomy from parents that begins in 
adolescence likely dissipates (Arnett, 2000), ameliorating intergroup salience in the parent-child relationship. As such, the interpersonal and intergroup salience of parent-relationships may fluctuate across the lifespan.

Intergroup dynamics in parent-child relationships may also be characterized by differences in racial or ethnic identities, (Soliz, Thorson, \& Rittenour, 2009), age, social class (Soliz \& Rittenour, 2012), and religious beliefs (Colaner et al., 2014). For example, Soliz et al. (2009) found when parents and grandparents acknowledged an individual's multiracial/ethnic background, it ameliorated intergroup salience in their relationships (Soliz et al., 2009). Also, supportive communication and self-disclosure in multiracial/ethnic families was positively related to relationship solidarity (Soliz et al., 2009). Similarly, parents' support and respect of their child's divergent religious beliefs were associated with higher levels of parent-child relationship satisfaction and feelings of a shared family identity (Colaner et al., 2014).

A child's coming out may heighten intergroup salience in the parent-child relationship. When a child comes out, it might especially exasperate intergroup salience in parent-child relationships in which parents' values, beliefs, or understandings of gender and sexuality conflict with the child's disclosed identity. Previous research demonstrates that individuals with more traditional family values (i.e., heteronormative cultural expectations toward gender roles, child bearing, etc.) and religious beliefs tend to be less supportive of SGM identities (Dunlap, 2014; Newman \& Muzzonigro, 2003; Rosenfeld et al., 2012). Thus, religious beliefs and cultural values play central roles in determining the intergroup salience a coming out disclosure may ignite, as these values are related to parents' reactions and adaptability to a child's coming out (Dunlap, 2014; Jenkins, 2008; Oswald, 2000). In order to more positively adjust to a child's revelation, parents often "stretch themselves" to open their minds, question their values, and 
adopt new perspectives on gender and sexuality (Gonzalez et al., 2013, p. 239). This enables parents to take tangible steps to learn about their child's identity and how to best support their child (Butauski \& Horstman, 2018; Gonzalez et al., 2013).

\section{Intergroup Communication: Parents' Reactions to their Child's Coming Out}

Parents' reactions to their child's coming out are highly variable and likely partially dependent on the intergroup dynamics in the parent-child relationship. Some parents react to their child's coming out with positivity and support (Butauski \& Horstman, 2018), whereas some react negatively with responses ranging from expressing anger and homophobia to expelling the child from the home to physical attack (Lozano-Verduzco, 2016; Potoczniak et al., 2009; SavinWilliams, 2001; Willoughby et al., 2006). For example, Denes and Afifi (2014) found that some SGM individuals come out to their parents again after their initial coming out, especially when parents expressed denial of their SGM identity. SGM individuals chose to come out again in order to reinforce their identity, clarify facets of their identity, or disclose more information about their identity.

Negative reactions to a child's coming out sometimes color the parent-child relationship long after coming out. Muller (1987) found that post-coming out, many parent-child relationships were characterized by a "loving denial," or a loving parent-child relationship wherein parents hid their child's identity from others. This need to hide the child's SGM identity could negatively impact the child's self-concept if they feel their parents are ashamed of them (Savin-Williams, 2001). Muller (1987) also found that many parent-child relationships were characterized by “resentful denial," or parents' relational distancing from, as well as lack of connection with, their child after the child's coming out. Similarly, transgender individuals deal with unique challenges as family members struggle (or fail to) adjust to their transitions (Nuru, 
2014). On the other hand, parents often positively adjust to their child's coming out, allowing the parent-child relationship to recalibrate or, in some cases, grow stronger (Savin-Williams, 2001; Potoczniak et al., 2009). Many parents create transformative personal stories when reflecting on their adjustment to their child's coming out that often involve questioning deeply-held values (Gonzalez et al., 2013). This likely fosters their ability to recalibrate or strengthen their relationships with their child post-coming out (Tyler, 2015).

A child's initial coming out is a "revelation of intergroup distinctions" in the parent-child relationship (Soliz \& Rittenour, 2012, p. 335), but intergroup dynamics likely continue playing a role in the parent-child relationship beyond the initial coming out event. When parents' negative feelings towards an individual's revealed SGM identity endures after the initial coming out, this highlights explicit intergroup barriers to the relationship (Soliz \& Rittenour, 2012). Offspring also tend to have less traditional values toward gender roles in comparison to their parents (Cichy, Lefkowitz, \& Fingerman, 2007), which could also contribute to the intergroup nature of SGM individuals' parent-child relationships. Butauski (2018b) found that SGM individuals often experience communication apprehension toward parent-child relationships characterized by intergroup salience. Participants explained they were especially guarded in discussing topics relative to gender, sexuality, religion, and politics because communicating about these topics often further emphasized their intergroup differences.

Overall, there is an inherently intergroup nature to these parent-child relationships based on parents' cisgender, heterosexual identities and children's SGM identities. Beyond the initial coming out event, parents likely exercise accommodative communication to foster a healthy communication and relationship environment with their child. As such, the current study uses CAT to explore intergroup dynamics in the parent-child relationships of SGM adult children who 
have already come out to their parents. Specifically, the current study examines SGM adult children's perceptions of their parents' accommodative communication in relation to SGM adult children's mental health and CPCA.

\section{Communication Accommodation Theory}

CAT is a versatile theory rooted in social psychology and is the primary framework used to guide investigations of intergroup communication (Giles \& Soliz, 2015; Pitts \& Harwood, 2015). At large, CAT describes how communication processes facilitate conversational partners' identity, relational, and message goals (Pitts \& Harwood, 2015). Pitts and Harwood (2015) explain that individuals use communication "to coordinate and align their communicative efforts (accommodation), to distance and/or misalign communication (nonaccommodation), or to hold the line (maintenance)," (p. 89). Put differently, CAT helps identify the extent to which communication enhances, ameliorates, or maintains intergroup salience (Harwood et al., 2006; Pitts \& Harwood, 2015).

Based on the historic assumptions of CAT, communication is the mechanism for convergence, divergence, or maintenance in intergroup interactions. Convergence references accommodative communication strategies used to adapt one's communication in ways that convey similarities to another's behaviors (Soliz \& Giles, 2014). Convergence is enacted to seek approval from another, promote affiliation with another, or highlight interpersonal similarities to reduce social distance. In doing so, individuals may modify their communication based on the characteristics of their conversational partner and adjust their communication to show respect for or affiliation with their conversational partner's social group. On the other hand, individuals may engage in nonaccommodative communication that emphasizes contrasting group identities and fosters divergence from their conversational partners (Harwood \& Giles, 2005). Individuals may 
also communicate for maintenance or communicate in ways that are consistent with how they typically speak, regardless of the communication behaviors or social identities of the interlocutor (Soliz \& Giles, 2014).

Accommodative communication behaviors show acknowledgement and respect for others' social identities (Gallois et al., 2005; Harwood, 2000). Communication accommodation underscores how individuals attune their communication behaviors in ways that meets the needs and desires of their conversational partners (Soliz \& Giles, 2014). Individuals can be accommodating by demonstrating care and concern through supportive communication (Burleson \& MacGeorge, 2002; Soliz et al., 2009), respecting divergent values (Colaner, Soliz, \& Nelson, 2014), selecting appropriate topics of discussion (Harwood, Soliz, \& Lin, 2006), and exercising other linguistic, paralinguistic, discursive, and nonverbal adaptations (Gallois et al., 2005; Harwood, 2000).

Accommodative communication illustrates one's attempts to meet and respect the needs of their conversational partner's social identity, whereas non-accommodative communication, intentionally or unknowingly, does not meet and respect the needs of the conversation partner's social identity. Nonaccommodative communication behaviors illustrate a failure to attune one's communication behaviors to meet the needs and desires of a conversational partner. In the context of intergenerational communication, older adults' painful disclosures that can make younger adults feel uncomfortable reflects nonaccommodative communication and younger adults' use of patronizing behaviors, such as speaking slower and using less complex language, reflects nonaccommodation (Coupland, Coupland, Giles, Henwood, \& Wiemann, 1988). Overall, nonaccommodative communication emphasizes divergent social identities and values and may involve making inappropriate self-disclosures, giving unwanted advice (Colaner et al., 
2014; Rittenour \& Soliz, 2009), and/or engaging in argumentative or aggressive behaviors (Mikkelson \& Hesse, 2009).

Although people often value communicating consistently across contexts, CAT suggests that communicating in the same ways across all situations can be inappropriate and ineffective (Giles, 2014; Spitzberg \& Cupach, 1984). Competent communicators will instead adapt to the context of interactions at hand with their relationships to interlocutors in mind (Pitts \& Giles, 2008) illustrating their accommodation competence (Pitts \& Harwood, 2015). In other words, accommodative communication behaviors help meet the needs of the situational and relational context of an interaction. Thus, CAT broadly and implicitly functions as a theory of communication competence because it guides scholarly understanding of when and how accommodation facilitates identity, relational, and interactional goals (Pitts \& Harwood, 2015).

In the context of SGM adult children's parent-child relationships, parents' accommodative communication illustrates parents' abilities to meet the needs of and maintain a healthy relationship with their child. As such, parents' accommodative communication behaviors are likely central to SGM adult children's mental health and CPCA. Research evidences the importance of parents' support of and positive adjustment to their child's SGM identity (Baiocco et al. 2015; Baptist \& Allen, 2008; Ryan et al., 2009) and asserts that communication accommodation is competent communication that fosters a more productive communication environment and satisfying relational climate (Colaner et al., 2014; Pitts \& Harwood, 2015; Soliz et al., 2010; Soliz \& Harwood, 2006). Taken together, the current study investigates how parents' accommodative communication relates to SGM adult children's mental health and levels of CPCA.

\section{Parents' Accommodative Communication with SGM Adult Children}


Parents' accommodative communication behaviors convey their acceptance and support of their child, as well as their ability to facilitate a supportive, productive communication environment with their child. The current study focuses on SGM adult children's perceptions of two parental communication accommodation behaviors. First, the current study assesses SGM offspring's perceptions of their parents' respect for divergent values - or accommodative communication conveying recognition and regard for their child's values and opinions that may diverge from their own - and SGM offspring's perceptions of their parents' SGM identity support, or accommodative communication illustrating explicit support of their child's SGM identity. The following sections detail the rationale for examining these specific accommodation behaviors in relation to SGM offspring's mental health and CPCA.

\section{Respect for Divergent Values and SGM Adult Children's Mental Health}

Individuals with different social identities often have corresponding differences in values. Thus, conveying respect for divergent values in intergroup interactions is an important accommodative communication behavior. Showing respect for divergent values of one's conversational partner demonstrates one's efforts to meet and respect the needs of their conversational partner's social identity (Colaner et al., 2014; Soliz et al., 2010). Communicating in ways that show respect for divergent values involves demonstrating recognition of and appreciation for another person's opinions and perspectives in contexts where conversational partners have dissimilar perspectives. Showing respect for divergent values can foster relationship satisfaction and emphasize conversational partners' shared group identities. For example, in the context of intergroup parent-child relationships based on religious differences, Colaner et al. (2014) found that parents' respect for their child's divergent religious values was 
related to higher levels of relationship satisfaction and shared family identity. Similarly, Soliz et al. (2010) found that heterosexual family members' perceptions of gay and lesbian family members' respect for divergent values was linked to higher levels of relationship satisfaction and lower levels of intergroup anxiety.

The intergroup nature of SGM individuals' parent-child relationships may be composed of a variety of divergent values based on their distinct social identities. For example, SGM individuals may different perspectives on gender and sexuality in comparison to their cisgender, heterosexual counterparts (Soliz et al., 2010). Divergent values in SGM adult children's parentchild relationships are likely salient to relationships in which parents' struggle to make sense of and accept new perspectives on gender and sexuality (Savin-Williams, 2001, 2005). SGM individuals may also characterize the intergroup nature of their parent-child relationships based on distinct political and religious values relative to their SGM identity, such as having different opinions on human rights, politics, religion, and morality in comparison to their parents (Butauski, 2018). Parent-child generational differences may also factor into the divergent values within SGM adult children's parent-child relationships (Grierson \& Smith, 2005; Soliz \& Rittenour, 2012; Tyler, 2015). For example, elder generations grew up surrounded by much different cultural values surrounding gender and sexuality in comparison to younger generations (Dunlap, 2015; Grierson \& Smith, 2005).

Parents' respect for their child's divergent values demonstrates their efforts to meet and respect the needs of their child's social identity and the values relative to their child's identity. Thus, SGM adult children's perceptions of their parents' respect for their divergent values is likely associated with SGM adult children's mental health. For example, behaviors that demonstrate parents' acceptance of their child's SGM identity, such as embracing and 
complimenting their child's gender nonconformity or openly discussing topics related to their child's identity, are associated with higher levels of self-esteem among SGM offspring (Ryan et al., 2010).

When parents show respect for their SGM child's divergent values, they are, in a way, illustrating support and thoughtful regard for their child's values, opinions, and perspectives, many of which may correspond with their child's SGM identity. Communicating respect for divergent values illustrates person-centered communication in that it is adaptive and accommodating to a conversational partner's needs (Jones \& Bodie, 2014). Parents' respect for their SGM children's divergent values is supportive, and thus, is likely associated with SGM offspring's mental health, as parental support is consistently linked to SGM offspring's mental health (Baiocco et al., 2015; Reeves et al., 2010; Ryan et al., 2009; Ryan et al., 2010; SavinWilliams, 1989). As such, the first hypothesis posits that SGM adult children's perceptions of their parents' respect for divergent values is related to lower levels of depression and anxiety:

H1: Perceptions of parents' respect for divergent values is negatively related to SGM adult children's (a) depression and (b) anxiety.

\section{SGM Identity Support and SGM Adult Children's Mental Health}

Given the importance of parents' support of their child's SGM identity to their child's well-being (Savin-Williams, 1989; Ryan et al., 2009; Ryan et al., 2010), the current study also assesses SGM adult children's perceptions of their parents' SGM identity support in relation to their mental health. Explicit SGM identity support is often lacking or unavailable to SGM individuals, especially from their families (Doty et al., 2010). However, research suggests that parents' direct support of their child's SGM identity is extremely important to SGM individuals' abilities to develop a positive sense of self (Savin-Williams, 1989). Parents'support of their 
child's SGM identity links to better mental health outcomes for SGM individuals including higher levels of self-esteem (Mena \& Vaccaro, 2013), decreased psychological distress (Rosario et al., 2005), and decreased likelihood of experiencing suicidal ideation and attempting suicide (Ryan et al., 2010). Because research consistently evidences the importance of SGM identity support to SGM offspring's well-being, the current study first aims to assess SGM adult children's perceptions of their parents' SGM identity support as is relates to SGM offspring's mental health, assessed by their levels of depression and anxiety.

Although parents' initial supportive reactions to their child's coming is undeniably important, (Savin-Williams, 1989; Ryan et al., 2009; Willoughby et al., 2006), parental support of a child's SGM identity may develop over time (Gonzalez et al., 2013; Grafsky, 2014; Saltzburg, 2009; Tyler, 2015). As a child's identity evolves, parents' concerns shift and the parent-child relationship continues to adjust (Tyler, 2015). The evolution of their identities occurs as they start dating or dressing in new ways or come to understand different facets of their identity (e.g., coming out as lesbian, then later as transgender) (Tyler, 2015). As SGM offspring's identities evolve and parents' concerns shift, their support of their child's SGM identity may fluctuate. For example, parents' may initially have great uncertainty about their child's well-being (e.g., worrying about them facing discrimination), as well as grief regarding their child's future (e.g., whether they will get married or have children) (Butauski \& Horstman, 2018; Tyler, 2015). These concerns may dissipate over time as parents adjust and reemerge when their child develops romantic relationships. Once their child has a romantic partner, new concerns arise about how parents might feel about the romantic partner and how (or whether to) integrate the partner into the family (Tyler, 2015). Overall, parents often need time to positively 
adjust to their child's coming out and after coming out, SGM individuals' identities continue to evolve.

Parent-child relationships, in general, are dynamic and continually evolving across the lifespan. The dynamics and evolution of SGM offspring's parent-child relationships can be uniquely challenging as offspring's SGM identities continue to develop and parents' concerns continue to shift beyond the child's initial coming out (Tyler, 2015). Parents' SGM identity support likely continues to be an important factor contributing to SGM offspring's mental health outcomes beyond the child's initial coming out event. Because of this, it is important to consider how SGM adult children's perceptions of their parents' SGM identity support relate to SGM adult children's mental health, assessed by their levels of anxiety and depression. In doing so, the second hypothesis posits that SGM adult children's perceptions of their parents' SGM identity support is negatively related to SGM adult children's depression and anxiety:

H2: Perceptions of parents' SGM identity support is negatively related to SGM adult children's (a) depression and (b) anxiety.

\section{Communication Accommodation and CPCA}

Communication apprehension is broadly defined as being afraid of or feeling anxious toward real or anticipated speeches or interactions (Luchetti et al., 2002; McCroskey, 1976). $C P C A$ references offspring's communication apprehension toward real or anticipated interactions with their parents (Luchetti et al., 2002). Children experiencing CPCA are less likely to share information with (Luchetti et al., 2002) and seek support from (Cascio et al., 2013) their parents. Consequently, CPCA undermines parent-child relational quality and children's willingness to openly communicate with their parents (Cascio et al., 2013; Luchetti et al., 2002). 
There are a variety of explanations for experiences of CPCA (Aloia \& Strutzenburg, 2019). Some researchers suggest that CPCA is the result of insecure attachments in the parentchild relationship (Critchfield \& Benjamin, 2008), whereas others suggest that communication apprehension is learned from modeling parents' behaviors (Bandura, 1973; Ayres, 1988). Another explanation is that CPCA stems from insecure, risky, or unhealthy parent-child interactions (Aloia \& Strutzenburg, 2019; Butauski, 2018b). For example, Aloia and Strutzenburg (2019) found that parental alienation - or the processes through which one parent psychologically manipulates their child with aims to ostracize the other parent - in childhood is linked with CPCA in adulthood. The significant, positive relationship between experiencing parental alienation in childhood and CPCA in adulthood was more potent when participants had lower levels of self-esteem.

Scholars have pinpointed a variety of causes of CPCA but have yet to investigate parental communication behaviors that may reduce CPCA. Because accommodative communication behaviors are used to meet the needs of relational partners (Colaner et al., 2014; Pitts \& Harwood, 2015; Soliz et al., 2010), it is likely that parents' communication accommodation is linked to decreased levels of CPCA. In the context of SGM adult children's parent-child relationships, parents' accommodative communication demonstrates parents' abilities to acknowledge and respect their child's SGM identity and maintain a healthy relationship with their child. SGM adult children's perceptions of their parents' accommodative communication behaviors likely fosters a relationship in which SGM adult children feel comfortable engaging in open communication with their parents. In other words, when SGM adult children feel their parents' communication is accommodating and conveys support of their SGM identity and respect for their divergent values, SGM adult children likely feel less CPCA. On the other hand, 
a lack of parental communication accommodation, or communication that fails to meet the needs and desires of SGM adult children, likely links to higher levels of CPCA.

Thus, this investigation aims to assess SGM adult children's perceptions of their parents' accommodative communication in relation to SGM adult children's CPCA. Investigating the role of parents' accommodative communication behaviors in relation to SGM adult children's CPCA is important because CPCA is indicative of a precarious parent-child relationship (Aloia \& Strutzenberg, 2019; Beatty \& Dobos, 1992). In doing so, SGM adult children's perceptions of their parents' respect for divergent values and SGM identity support are assessed in relation to SGM adult children's CPCA.

First, the current study hypothesizes that SGM adult children's perceptions of parents' respect for divergent values is negatively related to SGM adult children's CPCA. When parents communicate in ways that show respect for the child's beliefs, opinions, and values, their children likely feel more comfortable engaging in open communication with their parents. Offspring are often avoid discussing certain topics with their parents when discussions could lead to personal (i.e., hurt feelings) or relational harm (i.e., conflict) (Guerrero \& Afifi, 1995). For example, SGM adults reported avoiding a variety of different topics, especially those regarding divergent values (e.g., religion, politics), and attempting to keep conversations at "surface level" in interactions with their parents (Butauski, 2018). SGM adults were motivated to communicate with their parents in this way because of negative experiences in prior parent-child interactions. However, when parents engage in accommodative communication that conveys respect for divergent values, this likely aids in decreasing CPCA. In doing so, the third hypothesis posits: 
H3: SGM adult children's perceptions of parents' respect for divergent values is negatively related to SGM adult children's CPCA.

Second, the current study hypothesizes that SGM adult children's perceptions of parents' SGM identity support is negatively related to SGM adult children's CPCA. When parents communicate in ways that show explicit support of their child's SGM identity, it is likely that SGM offspring will feel more comfortable openly communicating. Feeling that parents' support their SGM identity is likely linked to decreased levels of CPCA because parents' support provides them with positive reappraisals of self (Savin-Williams, 1998). Further, parents' SGM identity support highlights parents' efforts to meet the needs of their child by acknowledging, affirming, and supporting their child's SGM identity. As such, it is hypothesized that SGM adult children's perceptions of their parents' SGM identity support is negatively related to their levels of $C P C A$, and the fourth hypothesis is:

H4: SGM adult children's perceptions of parents' SGM identity support is negatively related to SGM adult children's CPCA.

\section{CPCA and SGM Adult Children's Mental Health}

Previous research shows that CPCA is related to children's distress (Wright, 2000), decreased self-esteem (Cascio et al., 2013), and lower levels of parent-child relationship satisfaction (Aloia \& Strutzenburg, 2019; Luchetti, 2002). Because open, supportive parent-child relationships are integral to SGM offspring's well-being, it is likely that CPCA in SGM adult children's parent-child relationships is especially deleterious to their mental health (SavinWilliams, 1998; Ryan et al., 2010). The experience of CPCA suggests a precarious parent-child relationship in which parent-child communication is anxiety-inducing and uncomfortable for children (Butauski, 2018; Luchetti et al., 2002). CPCA in SGM adult children's parent-child 
relationships could stem from a variety of factors including, but not limited to, insecure attachments to their parents (Critchfield \& Benjamin, 2008), experiences of parental alienation in their childhood (Aloia \& Strutzenburg, 2019), and prior negative parent-child interactions (Butauski, 2018b).

When SGM adult children experience high levels of CPCA, this suggests that the parentchild communication climate is not characterized by supportive, open communication and may be indicative of relationships in which SGM adult children cannot comfortably and authentically enact their identities. For example, Butauski (2018a) found that when parents tried to interfere with or change their emerging adult children's career goals and religious and political beliefs, children were more likely to avoid discussing these topics for self- and relationship-protection. Emerging adults in the study were likely experiencing CPCA because of their topic avoidance motivations for self- and relational-protection. However, it is important to note that because CPCA is associated with less information sharing in the parent-child relationship, it may be indicative of functional topic avoidance that protects social bonds (Caughlin \& Afifi, 2004). Although topic avoidance can be functional and provide a healthy balance of openness and closedness in relationships, chronic topic avoidance can be distressing and harmful to relationships (Caughlin \& Petronio, 2004; Petronio, 2002).

Experiencing CPCA is related to distress (Wright, 2000) and could be especially distressing for SGM individuals if they feel their parents are not supportive and respectful of their SGM identity (Savin-Williams, 2001, 2005). Research guided by the communication theory of identity suggests that communication apprehension is associated with personal-enacted identity gaps (Jung, 2011, 2013). Personal-enacted identity gaps have been linked to depression (Jung \& Hecht, 2008) and reference a perceived difference between an individual's views of self 
(i.e., their identity) and how that individual expresses their identity when communicating with others. If a SGM individual is experiencing CPCA, it is also likely that they are communicating in ways that create, maintain, or accentuate experiences of personal-enacted identity gaps in their parent-child relationship. Put differently, SGM individuals experiencing CPCA may not be communicating with their parents in ways that express themselves accurately and authentically.

Taken together, research has shown that CPCA is distressing (Wright, 2000) and that communication apprehension is strongly associated with personal-enacted identity gaps (Jung, 2011, 2013), which are related to higher levels of depression (Jung \& Hecht, 2008).

Experiencing CPCA personal-enacted identity gaps is distressing and suggests offspring are navigating difficult parent-child relationships, in general. Experiencing CPCA is likely especially harmful to SGM individuals as supportive, healthy parent-child relationships function as an important protective factor for their well-being (Ryan et al., 2010; Savin-Williams, 1998, 2001, 2005). Thus, SGM adult children's experiencing CPCA likely have higher levels of depression and anxiety. In order to test this assumption, the fifth hypothesis is posited:

H5: SGM adult children's CPCA is positively related to their levels of (a) depression and (b) anxiety.

The final goal of the current study is to test CPCA as a mediating variable in the relationship between SGM adult children's perceptions of their parents' accommodative communication behaviors and SGM adult children's mental health. H1 posits that SGM adult children's perceptions of their parents' respect for divergent values and SGM identity support are negatively related to SGM adult children's levels of anxiety and depression and H2 asserts that SGM adult children's perceptions of their parents' respect for divergent values and SGM identity support are negatively related to SGM adult children's CPCA. H3 contends that SGM adult 
children's CPCA is positively related to their levels of anxiety and depression. Through creating a supportive communication environment characterized by lower levels of CPCA, parents' communication accommodation relates to more positive mental health outcomes. Conversely, when parental communication accommodation is lacking, it contributes to higher levels of CPCA which are related to more negative mental health outcomes or higher rates of depression and anxiety. As such, the final hypotheses propose that the relationship between SGM adult children's perceptions of their parents' accommodative communication behaviors and SGM adult children's mental health is mediated by CPCA (See Figure 1):

H6: The negative relationships between SGM adult children's perceptions of their parents' respect for divergent values and their levels of (a) depression and (b) anxiety are mediated by SGM adult children's CPCA.

H7: The negative relationships between SGM adult children's perceptions of their parents' SGM identity support and their levels of (a) depression and (b) anxiety are mediated by SGM adult children's CPCA.

In sum, the proposed model aims to identify how parents' accommodative behaviors create a more open, supportive communication environment, characterized by lower levels of CPCA, which in turn promotes better mental health outcomes. Parents' accommodative behaviors show respect and support of their SGM child's autonomy, which should contribute to lower levels of CPCA and promote more positive mental health outcomes assessed by their child's depression and anxiety, respectively. The model proposes that through lower levels of CPCA, parents' accommodative behaviors promote better mental health outcomes characterized by lower levels of depression and anxiety. 


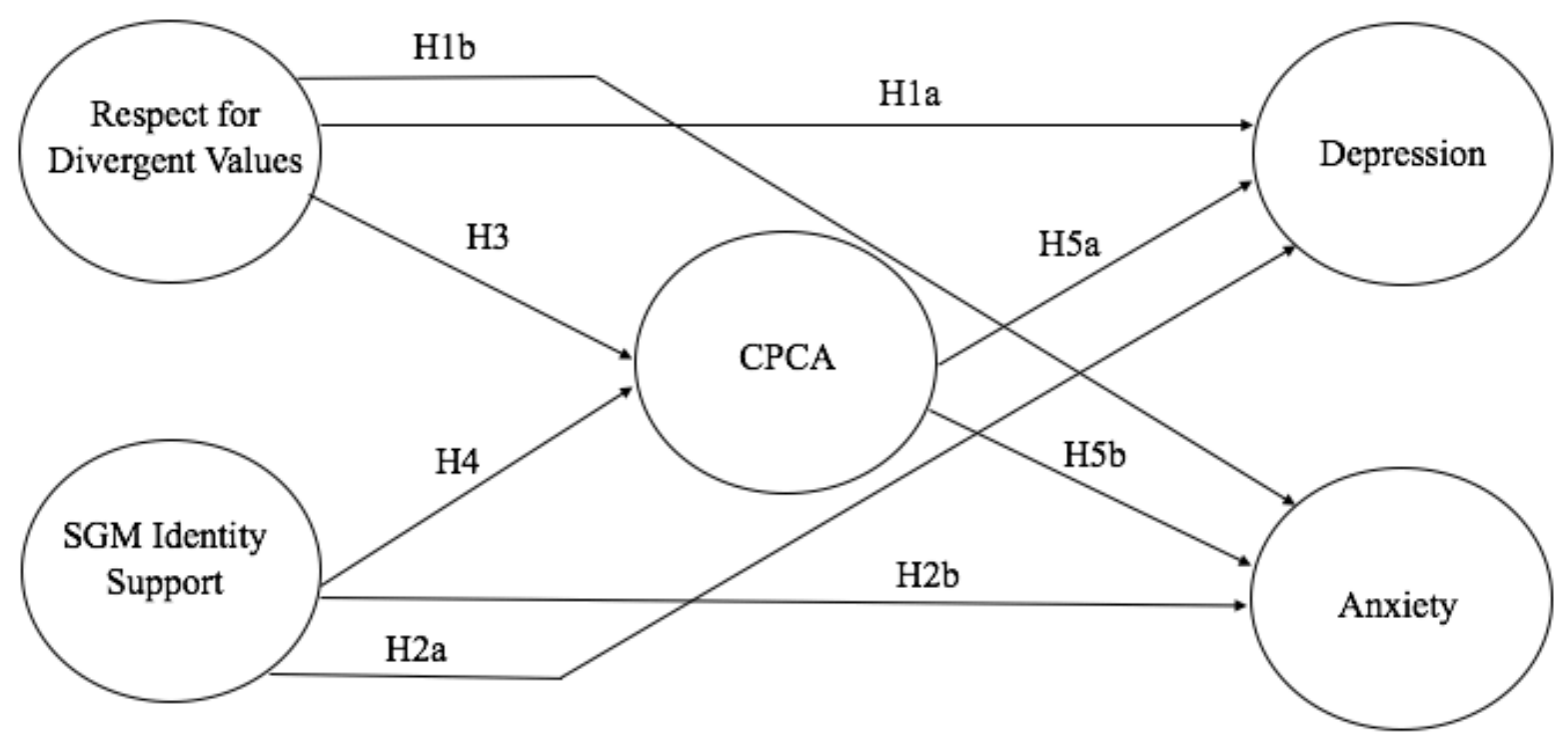

Figure 1. Hypothesized structural model. 


\section{CHAPTER 3: METHODS}

\section{Recruitment Procedures}

To participate in the current study, respondents be at least 18 years old, identify as an SGM individual, be out to their parents (i.e., have already disclosed SGM identity to their parents), and be willing to voluntarily complete an online survey about their parent-child communication. Participants' parents also had to identify as cisgender and heterosexual to capture the intergroup nature of the parent-child relationship. I used multiple web-based platforms to recruit participants $(n=199)$, including Reddit, Twitter, and Facebook. Previous research demonstrated that high quality data comparable to data gathered from undergraduate participants can be obtained through the web-based platform Reddit. The website includes a variety of sub-websites, or online communities, focusing on a vast range of content areas (Jamnik \& Lane, 2017). For example, Reddit "SampleSize” (Jamnik \& Lane, 2017) hosts over 40,000 subscribers gathered to be recruited to participate in survey research. Reddit LGBT is designed as a safe space for gender, sexual, and romantic minorities to discuss their experiences and hosts over 274,000 subscribers. I published recruitment posts for the current project to Reddit SampleSize, given its success in recruiting participants for previous research (Jamnik \& Lane, 2017), as well as Reddit LGBT with aims to specifically target potential SGM participants. A little more than half of the participants in this study were recruited through these sub-Reddit platforms $(n=110,55.3 \%)$.

The remainder of participants for the study were recruited through Facebook and Twitter, or heard about the study by "word of mouth" (e.g., a friend or instructor shared it). A local community organization serving the SGM community published three Facebook posts from their page inviting people to participate in the study, which resulted in recruiting just more than 20 percent of the sample for the current study $(n=49,24.6 \%)$. I also recruited participants through 
my personal Twitter account, recruiting less than six percent of the participants for the current study $(n=11,5.5 \%)$. Others reported that they were recruited by word of mouth $(n=14,7 \%)$ or did not report where they found out about the survey $(n=15,7.5 \%)$.

\section{Participants}

Participants' ages ranged from 18 to 61 years old $(M=29.6, S D=10.3)$. The age at which participants came out ranged from nine to 48 years old $(M=20.88, S D=6.35)$. On average, participants reported being out for just over eight years $(M=8.57, S D=8.69)$. Most identified their gender as cisgender female $(n=114,57.3 \%)$, followed by nonbinary, genderqueer, or gender-fluid $(n=29,14.6 \%)$, cisgender male $(n=26,13.1 \%)$, transgender female $(n=$ $15,7.5 \%)$, and transgender male ( $n=15,7.5 \%)$. In other words, 70 percent of the sample identified as cisgender $(n=140,70.4 \%)$, whereas the remainder of participants' gender identities fell under "transgender" as an umbrella term for transgender or gender nonconforming ( $n=59$, 29.6\%). Most of the participants identified as bisexual, pansexual, or queer $(n=106,53.3 \%)$, followed by gay or lesbian $(n=75,37.7 \%)$. The remainder of participants identified as asexual $(n=3,1.5 \%)$, aromantic $(n=1,0.5 \%)$, asexual and aromantic $(n=3,1.5 \%)$, demisexual $(n=3$, $1.5 \%)$, or self-described their sexual orientations $(n=8,5.5 \%)$ with a variety of labels including "demisexual and polyamorous," "bisexual aromantic," "queer asexual," "gay asexual," "asexual lesbian," "polysexual," "pansexual and asexual," and "more gay than bi." Nearly 85 percent of the participants reported their race as Caucasian/white $(n=168,84.4 \%)$, followed by mixed race $(n=23,11.5 \%)$, Asian $(n=3,1.5 \%)$, African American/black $(n=2,1.0 \%)$, Hispanic or Latino/a/x $(n=2,1.0 \%)$, and Native Hawaiian or Pacific Islander $(n=1,0.5 \%)$. 


\section{Procedures}

Participants completed an online survey that began with an informed consent page. Following the informed consent page, participants filled out demographic information before answering questions about their parent-child communication. The participants were presented with the following prompt to select the parent they would keep in mind as they finished the remainder of the survey:

In this section, we ask that you select the parent with whom you last communicated. The parent you selected could be a biological or adoptive parent or someone you consider your mother or father. Please select the parent with whom you last communicated. The remainder of the survey will ask you questions about this parent and your communication with them.

Most participants selected their mother $(n=155,77.9 \%)$, whereas the remainder selected their father $(n=44,22.1 \%)$. Of the parents selected, most were identified as a biological parent $(n=$ 190, 95.5\%), whereas some were identified as an adoptive parent $(n=6,3.0 \%)$, step-parent $(n=$ 2, 1.0\%), or another "important parental figure" $(n=1,0.5 \%)$. Participants were also asked, "On a scale from 0 to 100,100 meaning your parent has completely positive perceptions of lesbian, gay, bisexual, transgender, and queer (LGBTQ) community, how does your parent perceive the LGBTQ community?" Responses to this item revealed that participants, on average, felt their parents had slightly positive perceptions of the SGM community $(M=68.21, S D=27.70)$.

\section{Preliminary Analysis}

I first conducted bivariate correlational analyses to investigate relationships among the variables and check for collinearity (See Table 1). The bivariate correlational analyses demonstrated relationships among the variables as expected and also illustrated an extremely 
strong relationship between anxiety and depression, such that the variables would cause problems with collinearity in the structural model analysis. As such, I dropped the anxiety variable from the model analysis to focus solely on the depression variable. I chose to keep the depression variable over the anxiety variable because parents' communication plays a significant role in their child's reflected appraisals and negative reflected appraisals from parents is associated with higher levels of depression among SGM offspring (Savin-Williams, 1989).

Table 1. Bivariate Correlations

\begin{tabular}{lccccc}
\hline Variables & 1 & 2 & 3 & 4 & 5 \\
\hline (1) Respect & 1 & & & & \\
(2) Identity Support & $0.58^{* *}$ & 1 & & & \\
(3) CPCA & $-0.63^{* *}$ & $-.66^{* *}$ & 1 & & \\
(4) Depression & $-0.15^{*}$ & -0.12 & $0.22^{* *}$ & 1 & 1 \\
(5) Anxiety & $-0.15^{*}$ & -0.12 & $0.21^{* *}$ & $0.98^{* *}$ & 1 \\
$* p<.05 . * * p<.001$. & & & & &
\end{tabular}

\section{Measurement Model Analysis}

I used structural equation modeling (SEM) to test the current study's measurement structure and hypotheses. There are important advantages to using SEM for this analysis. SEM allows for analyzing all direct and indirect effects simultaneously. Additionally, SEM estimates latent variables from indicators instead of estimating composite variables constructed from the average of all scale items. Thus, measurement error in SEM is eliminated and estimates produced by SEM represent the true scores of latent relationships.

Using the two-step procedure recommended by Kline (2005), I first estimated a measurement model to examine item-level data and overall model fit. I used the lavaan package of R, which is an open-sourced statistical analysis program (Rosseel, 2012), to conduct structural 
equation modeling (SEM) analysis with robust ML estimation. Following the two-step procedure recommended by Kline (2005), I conducted a confirmatory factor analysis (CFA) to examine item-level fit and overall model fit among the variables. Each item functioned as an indicator of its latent variable. The CFA demonstrated poor model fit, $\chi^{2}(\mathrm{~N}=199,371)=710.21, \mathrm{p}<$ $.001, \chi^{2} / \mathrm{df}=1.08 \mathrm{CFI}=.93 ; \mathrm{RMSEA}=.07(\mathrm{CI}[0.05,0.07]), \mathrm{TLI}=.92, \mathrm{SRMR}=.05$. The $R^{2}$ statistics indicated three problematic items suggesting that these items were not measuring the intended constructs. Items that exhibited low variance explained by the variable $\left(R^{2}<.35\right)$. Removed items are discussed below in the measures. Items for respect for divergent values, CPCA, depression, and anxiety were then parceled. Parceling involves creating indicators comprised of the average of two or more items to identify each construct and reduce the number of parameter estimates in the model (Little, Cunningham, Shahar, \& Widaman, 2002). Without a pre-identified rationale for parceling, I constructed domain-representative parcels by dividing items into thirds wherein each parcel represented the whole domain of the latent construct (Little, Rhemtulla, Gibson, \& Schoemann, 2013). Parcels were not created for SGM identity support because only three items represented this construct and thus parceling is unnecessary.

After removing the three problematic items and parceling, the model demonstrated excellent model fit $\chi^{2}(\mathrm{~N}=199,48)=71.56, \mathrm{p}<.05, \chi^{2} / \mathrm{df}=1.09$, robust CFI $=.97$; robust RMSEA $=.04(C I[0.01,0.07])$, robust TLI $=.96$, robust SRMR $=.02$. See Table 2 for factor loadings.

\section{Measures}

Parents' respect for divergent values. To assess perceptions of parents' respect for divergent values, I modified the scale used by Colaner et al., (2014), which measured parents' respect for their child's divergent religious values. I modified the scale to assess parents' respect 
of SGM adult children's divergent values at large, which participants responded to on a fivepoint Likert-type scale $(1=$ strongly disagree; $5=$ strongly agree $)$. Modified scale items include: "My parent is respectful of my opinions in our conversations," "In our interactions, my parent takes my views and opinions into account," My parent is generally respectful of my beliefs when we talk about our opinions," and "My parent is tolerant of my beliefs when we disagree." In total, four items assessed parents' respect for divergent values $(M=4.22, S D=1.60, \alpha=0.94)$.

Parents' SGM identity support. To assess SGM adult children's perceptions of their parents' SGM identity support, I modified the scale used by Colaner et al., (2014), which measured parents' support of their child's religious beliefs, to assess parents' support of their child's SGM identity. Modified scale items include: "I know my parent supports my (SGM identity selected at beginning of survey) identity," "My parent does not pressure me to conform to heteronormativity (i.e., heterosexual and/or cisgender norms/expectations)," "My parent listens to me when I talk about topics related to my (SGM identity selected at beginning of survey) even though my parent doesn't support me identifying as this identity," and one reversecoded item "It is difficult to talk to my parent about topics related to my (SGM identity selected at beginning of survey) because my parent isn't fully supportive of it." Participants responded to these items on a five-point Likert-type scale $(1=$ strongly disagree; $5=$ strongly agree $)$. Item 4 ("My parent listens to me when I talk about topics related to my [SGM identity selected at beginning of survey] even though my parent doesn't support me identifying as this identity,") exhibited low variance explained by the variable $(<.35)$ and was thus removed from the measure. This item was likely problematic because it explicitly states that their parent is not supportive of their SGM identity. In total, three items were utilized to assess parents' SGM identity support $(M=3.21, S D=1.21, \alpha=0.87)$. 
Child-parent communication apprehension. Luchetti, Powers, and Love's (2002) 12item child-parent communication apprehension scale (CPCA) was responded to on a five-point Likert-type scale $(1=$ strongly disagree; 5 = strongly agree $)$. Higher scores illustrate higher levels of child-parent communication apprehension. Scale items include: "I feel strained when anticipating talks with my parent" and "I'm afraid to come right out and tell my parent what I mean," and reverse coded items such as "I have no fear telling my parent exactly how I feel" and "I have no anxiety telling my parent my needs." The $R^{2}$ statistics showed that Item 6 ("I am afraid to come right out and tell my parent exactly what I mean") exhibited low variance explained by the variable $(<.35)$. Thus, Item 6 was removed from the scale. This item was likely problematic due to its double-barreled construction (i.e., to "come right out and tell my parent exactly what I mean"). In total, 11 items assessed CPCA $(M=3.80, S D=0.94, \alpha=0.96)$.

Depression. Kroenke and Spitzer's (2002) widely used Brief Depression Severity Measure (PHQ-9) includes nine items to be responded to on a scale from one to four ( $1=$ not at all, $2=$ several days, $3=$ more than half the days, $4=$ nearly every day). Higher scores suggest higher frequencies of experiences of depression. The assessment asked respondents, "Over the last two weeks, how often have you been bothered by the following problems?" and included items such as "feeling down, depressed, or hopeless," "little interest or pleasure in doing things," and "trouble falling or staying asleep, or sleeping too much." The $R^{2}$ statistics showed that item 8 ("Moving or speaking so slowly that other people could have noticed? OR the opposite—-being so fidgety or restless that you have been moving around a lot more than usual") exhibited low variance explained by the item $(<.35)$ and was removed. The item was likely problematic because of its double-barreled construction such that it mentions two opposite behaviors in the same item. In total, eight items assessed participants' depression $(M=2.09, S D=0.80, \alpha=0.91)$. 
Anxiety. Spitzer, Kroenke, Williams, and Lowe's (2006) seven-item measure for assessing generalized anxiety disorder (GAD-7) was used to assess anxiety in the current study. Items are responded to on a scale one to four $(1=$ not at all, $2=$ several days, $3=$ more than half the days, 4 = nearly every day) with higher scores suggesting higher frequency of anxiety. Like the PHQ-9, the GAD-7 asked respondents, "Over the last two weeks, how often have you been bothered by the following problems?" and included items such as "worrying too much about different things," "feeling nervous, anxious or on edge," and "not being able to stop or control worrying." Because of collinearity with depression, this anxiety measure was not used in the SEM analysis $(M=2.20, S D=0.85, \alpha=0.92)$.

\section{Structural Model Analysis}

Per the second step in Kline's (2005) two-step procedure, I tested the hypothesized model in SEM using maximum likelihood estimation in the Lavaan software package for R studio (Rosseel, 2012). The structural model of the hypothesized Model 1 (see Figure 1) demonstrated good model fit $\chi^{2}(N=199,48)=71.56, p<.05, \chi^{2} / \mathrm{df}=1.09$, robust $\mathrm{CFI}=.99$; robust RMSEA $=.043(\mathrm{CI}[0.06,0.09])$, robust TLI $=.98$, robust $\mathrm{SRMR}=.02$. As recommended by Holbert and Gill (2015), the statistical significance of each path was tested using the chi-squared difference test of nested models to test hypothesized direct effects. This involved creating a nested model by constraining a path to equal zero and comparing it to the unconstrained model to assess the change in chi-square produced by imposing the zero-constraint on the path. Significant changes in chi-square (on one degree of freedom) illustrate that the path is significantly different from zero, demonstrating a significant relationship among the variables in the path. I used bootstrapping through lavaan (Rosseel, 2012) to test hypothesized indirect effects. Bootstrapping 
randomly draws 1,000 samples to generate standard error estimates at the $95 \%$ confidence interval and confidence intervals that do not contain zero indicate a significant indirect effect.

Table 2. Model fit for structural model

\begin{tabular}{ccccccc}
\hline & \multicolumn{2}{c}{ Loadings } & \multicolumn{2}{c}{ Residual } & $R^{2}$ \\
\hline & $\begin{array}{c}\text { Unstandardized } \\
\text { (SE) }\end{array}$ & Standardized & $\begin{array}{c}\text { Unstandardized } \\
\text { (SE) }\end{array}$ & Standardized \\
\hline $\begin{array}{c}\text { Respect for } \\
\text { Divergent Values }\end{array}$ & & & & & & \\
Item 1 & $1.80(0.09)$ & 0.93 & $0.53(0.13)$ & 0.14 & 0.86 \\
Parcel 1 & $1.86(0.10)$ & 0.91 & $0.68(0.24)$ & 0.17 & 0.83 \\
Parcel 2 & $1.96(0.09)$ & 0.92 & $0.70(0.15)$ & 0.15 & 0.85 \\
SGM Identity & & & & & \\
Support & $1.13(0.07)$ & 0.88 & $0.35(0.07)$ & 0.22 & 0.79 \\
Item 1 & $0.97(0.08)$ & 0.74 & $0.80(0.11)$ & 0.46 & 0.54 \\
Item 2 & $1.29(0.06)$ & 0.90 & $0.40(0.12)$ & 0.19 & 0.81 \\
Item 3 & & & & & \\
CPCA & $0.62(0.04)$ & 0.93 & $0.18(0.03)$ & 0.13 & 0.87 \\
Parcel 1 & $0.68(0.05)$ & 0.98 & $0.07(0.03)$ & 0.05 & 0.96 \\
Parcel 2 & $0.56(0.04)$ & 0.87 & $0.32(0.05)$ & 0.25 & 0.75 \\
Parcel 3 & & & & & \\
Depression & $0.80(0.04)$ & 0.93 & $0.11(0.03)$ & 0.14 & 0.86 \\
Parcel 1 & $0.76(0.04 \mathrm{f})$ & 0.90 & $0.14(0.02)$ & 0.19 & 0.92 \\
Parcel 2 & $0.69(0.05)$ & 0.86 & $0.17(0.02)$ & 0.26 & 0.74 \\
Parcel 3 & & & & &
\end{tabular}




\section{CHAPTER 4: RESULTS}

See Table 1 for bivariate correlations. See Table 3 for parameter estimates, standard errors, and chi square difference statistics. See Figure 2 for the tested structural model.

\section{Preliminary Analysis}

Preliminary bivariate correlational analyses showed a significant negative relationship between SGM adult children's perceptions of their parents' respect for divergent values and SGM adult children's depression and anxiety. SGM adult children's perceptions of their parents' SGM identity support was not related to SGM adult children's depression and anxiety. Bivariate correlational analyses demonstrated significant, negative relationships between SGM adult children's perceptions of their parents' respect for divergent values and CPCA, as well as $S G M$ identity support and CPCA. Finally, the results indicated a significant, positive relationship between SGM adult children's $C P C A$ and their depression and anxiety.

\section{Hypothesis Testing}

The first hypothesis proposed that parents' respect for divergent values is negatively related to SGM adult children's levels of depression. Results indicated non-significant negative relationships between parents' respect for divergent values and SGM adult children's depression $\left(\beta=-0.05, \Delta \chi^{2}(1)=0.12, p>.05\right)$. Therefore, $\mathrm{H} 1$ was not supported.

Hypothesis two posited that parents' SGM identity support is negatively related to SGM adult children's levels of depression. Results indicate non-significant relationships between parents' SGM identity support and depression $\left(\beta=0.09, \Delta \chi^{2}(1)=0.40, p>.05\right)$. As such, H2 was not supported.

The third hypothesis proposed that parents' respect for divergent values is negatively related to SGM adult children's CPCA. Results demonstrated that higher levels of parents' 
respect for divergent values were significantly, negatively related to SGM adult children's CPCA $\left(\beta=-0.56, \Delta \chi^{2}(1)=27.58, p<.001\right)$. In other words, when SGM adult children perceived that their parents communicated respect for their divergent values, they experienced significantly lower levels of CPCA. As such, H3 was supported.

Hypothesis four posited that parents' SGM identity support is negatively related to SGM adult children's CPCA. Results demonstrated that perceptions of parents' SGM identity support was significantly, negatively associated with SGM adult children's CPCA $\left(\beta=-0.33, \Delta \chi^{2}(1)=\right.$ $10.13, p<.01)$. Put differently, higher levels of parents' SGM identity support were significantly related to lower levels of SGM adult children's CPCA. Thus, H4 was supported.

The fifth hypothesis posited that SGM adult children's CPCA is positively related to their depression. Results demonstrated a significant, positive relationship between SGM adult children's CPCA and depression $\left(\beta=0.24, \Delta \chi^{2}(1)=3.80, p=.05\right)$. In other words, SGM adult children's experiences of CPCA were associated with their depression. Thus, H5 was supported. Hypothesis six suggested that SGM adult children's CPCA mediates the relationship between parents' respect for divergent values and their depression. Results indicated the mediation for depression was approaching significance $(\beta=-0.14, p=.08$, CI [-0.32, 0.03]), $)$. Thus, H6 was not supported.

Hypothesis seven suggested that SGM adult children's CPCA mediates the relationship between parents' SGM identity support and adult children's experiences of depression. Results did not indicate support for the mediation for depression $(\beta=-0.08, p>.05$, CI $[-0.23,0.01])$, H7 was not supported. 
Table 3. Structural equation modeling results with standardized coefficients

\begin{tabular}{lccccc}
\hline Parameter Estimate & $\beta$ & $p$ & $S E$ & $\Delta \chi 2$ & $p$ \\
\hline Respect - Depression & -0.05 & 0.82 & 0.15 & 0.12 & 0.82 \\
Identity Support - Depression & 0.09 & 0.57 & 0.14 & 0.40 & 0.56 \\
Respect - CPCA* & -0.56 & 0.00 & 0.17 & 27.58 & 0.00 \\
Identity Support - CPCA* & -0.33 & 0.03 & 0.15 & 10.13 & 0.00 \\
CPCA — Depression* & 0.24 & 0.10 & 0.08 & 4.01 & 0.05 \\
\hline
\end{tabular}

* denotes significant relationship

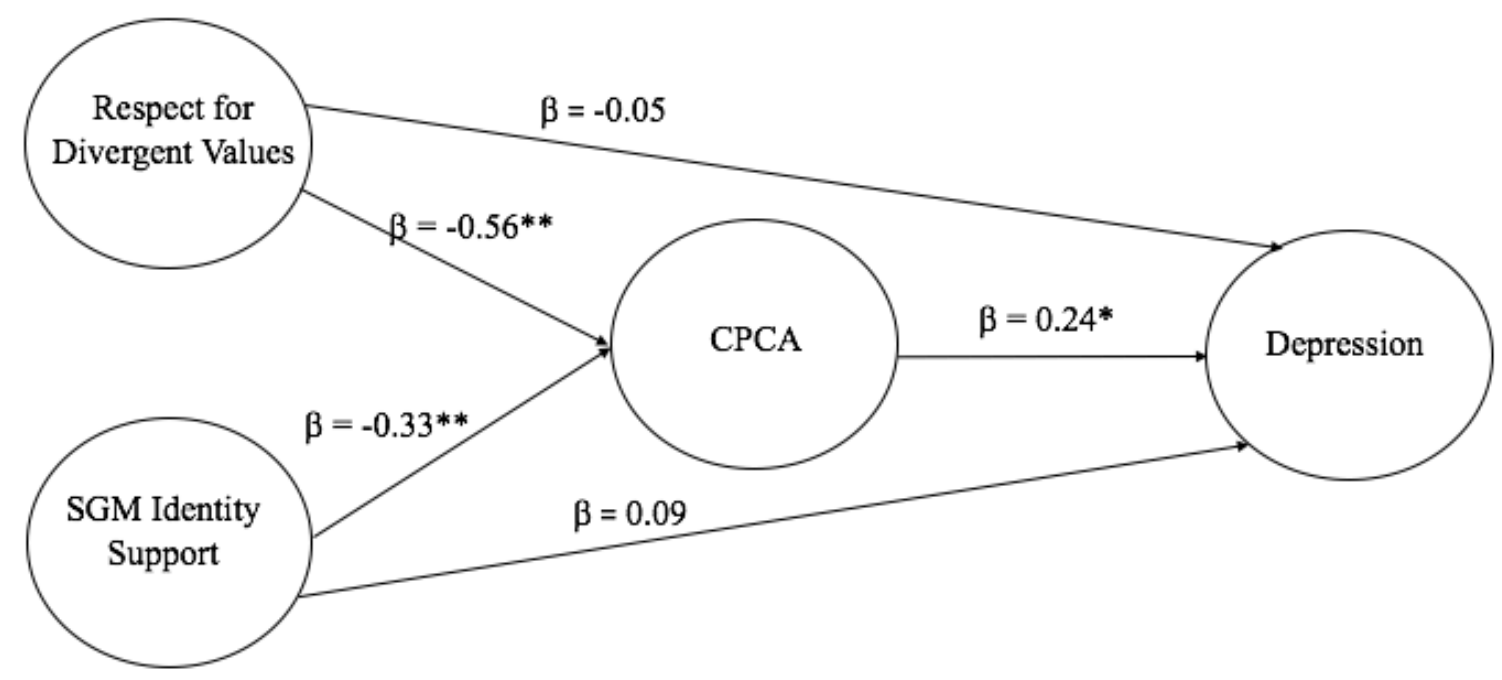

Figure 2. Tested structural model.

${ }^{*} p=.05 .{ }^{* *} p<.001$. 


\section{CHAPTER 5: DISCUSSION}

Based on intergroup theorizing, the current study investigated the role of parent-child communication in SGM adult children's mental health. Because of the intergroup nature of SGM adult children's relationships with their non-SGM parents, the current study focused on examining SGM adult children's perceptions of their parent's accommodative communication in relation to SGM adult children's mental health and CPCA. Findings illustrated that perceptions of parents' SGM identity support and respect for divergent values were not significantly related to SGM adult children's depression and anxiety. However, perceptions of parents' SGM identity support and respect for divergent values were significantly related to lower levels of SGM adult children's CPCA, which was related to higher rates of depression among participants. Although the mediation was only approaching significance, this model illustrates how parents' accommodative communication behaviors, which show respect for and support of their child's autonomy, creates a healthy communication environment characterized by lower levels of CPCA that positively contributes to the child's mental health.

These findings make important contributions to the growing body of research on SGM individuals' parent-child relationships and intergroup family communication. The current study contributes to scholarship in three important ways: by (a) evidencing the positive role of parents' accommodative communication in intergroup parent-child relationships; (b) highlighting the importance of the role of communication apprehension in close intergroup family relationships; and (c) showcasing how parent-child communication relates to SGM adult children's mental health beyond their initial coming out. With these contributions, the current study serves as a springboard for future research on intergroup dynamics in parent-child relationships and processes promoting resilience among SGM individuals. The following sections detail the 
contributions of this work and directions for future research, as well as the limitations of the current study.

\section{The Positive Role of Parents' Communication Accommodation}

The current study contributes to research exploring intergroup family relationships (Soliz \& Harwood, 2003; Soliz et al., 2010; Soliz, 2007), and more specifically, intergroup parent-child relationships (Colaner et al., 2014). As hypothesized in the current study, SGM adult children's perceptions of their parents' respect for divergent values and SGM identity support were related to significantly lower levels of CPCA after the children's initial coming out. These findings highlight the importance of parents' accommodative communication in creating a supportive, affirming communication climate. In doing so, these findings provide further evidence of the positive role of communication accommodation in family relationships (Colaner et al., 2014; Rittenour \& Soliz, 2009; Soliz, 2007) and have implications for theorizing regarding respect for divergent values and communicating identity support.

Intergroup theorizing examines how intergroup salience motivates individuals to interact with others (Gallois, Watson, \& Giles, 2018) and the current study's findings underscore parents' motivation to meet the needs of their children and foster healthy parent-child relationship dynamics. Accommodative communication behaviors demonstrate an individual's efforts to acknowledge and respect another individual's social identity(ies) (Gallois et al., 2005; Harwood, 2000; Soliz \& Giles, 2014) and communicate in ways that prioritize the needs of the interlocutor and the individual's relationship with the interlocutor (Pitts \& Harwood, 2015).

Parents' accommodative communication behaviors demonstrated their willingness to prioritize their child's needs and their relationship to their child, rather than emphasizing their child's outgroup membership (i.e., SGM identity). In doing so, parents demonstrate their 
resilience in positively adjusting to their child's revealed SGM identity (Butauski \& Horstman, 2018), which can often serve as a significant intergroup barrier (Soliz \& Rittenour, 2012). Instead of communicating in ways that exasperate intergroup barriers (i.e., nonaccommodative communication), SGM adult children perceived their parents to communicate support and respect for their SGM identity and their potentially divergent values based on their SGM identity. This highlights the power of intragroup dynamics, or the interpersonal salience of the parent-child relationship (Harwood et al., 2006; Soliz \& Rittenour, 2012), and further highlights the positive contributions of communication accommodation to intergroup family relationships (Harwood, 2000; Soliz \& Rittenour, 2012).

Parents who communicate respect for divergent values show recognition and appreciation for their SGM adult children's values, beliefs, and opinions. Unlike from SGM identity support, which solely communicates support of the child's SGM identity, respect for divergent values communicates affirmation of the child's identity as a whole, including parts of their identity that may diverge from parents' ideologies. This allows SGM adult children to feel more comfortable and less apprehensive about interacting with their parents. Parents' respect for SGM adult children's divergent values also honors SGM adult children's autonomy from their parents because it demonstrates acknowledgement and trust of their children's decisions and values. In doing so, this respect for divergent values may ignite positive reflected appraisals for the children, which are essential to children's well-being (Savin-Williams, 1989). This respect affirms offspring's autonomy from their parents, which becomes more important as they age through adolescence and early adulthood (Arnett, 2000), and allows them to feel comfortable interacting and anticipating interaction with their parents. 
On the other hand, when parents try to interfere with offspring's choices and beliefs or do not show respect for offspring's divergent values, their offspring are more motivated to avoid discussions surrounding those topics to protect themselves and the parent-child relationship (Butauski, 2018a). This suggests offspring are experiencing CPCA. When parents interfere, they are suggesting they do not trust their children's ability to make important decisions and explore or adhere to divergent values. Respectful accommodation does the opposite. Parents' respect for divergent values highlights their awareness and commendation of children's values. In doing so, parents' foster a more open and supportive communication climate in which SGM adult children feel more comfortable and less motivated to avoid openly communicating with their parents.

Showing respect for divergent values in close intergroup family relationships is essential to fostering open communication because it ameliorates intergroup anxiety or intergroup salience (Soliz et al., 2010). For example, engaging in respectful accommodation may be especially important in close family relationships characterized by differences in political ideologies. Differences in political ideology seem omnipresent and are likely present in many family and romantic relationships (Afifi, \& Zamanzadeh, Harrison, \& Perez-Torez, 2018; Reineke, 2009). Engaging in respectful accommodation in close relationships characterized by polarized political ideologies may be fundamental in fostering open, less combative communication when discussing topics relative to these ideologies. This respectful accommodation may be particularly essential to parent-child relationships. As offspring mature and seek to develop a stable ego identity, which involves exploring their beliefs and seeking direction for their lives, they may grow to adhere to values and beliefs that diverge from their upbringing (Arnett, 2000; Erikson, 1967; 1968). This divergence can cause tension and lead to less open communication in the parent-child relationship (Butauski, 2018a). The current study's findings signify the importance 
of parents' respectful accommodation in fostering an open communication climate and informs future work concerned with divergent values in this relational context.

In the same vein, communicating explicit support of a child's SGM identity shows parents' recognition and acceptance of their child's SGM identity and autonomy. Parents' SGM identity support ignites positive reappraisals fostering SGM offspring's abilities to form positive senses of self (Savin-Williams, 1989, 2001, 2005) and comfort in engaging in open communication with their parents (Butauski, 2018a). Explicit SGM identity support and affirmation is often lacking or completely unavailable to SGM individuals, but is an important factor contributing to SGM individuals' resilience (Doty et al., 2010). Parents who show support of their child's SGM identity affirm their child's identity and show unconditional love and support for their child (Butauski \& Horstman, 2018). Parents' identity support highlights parents' resilience, as well as cultivates resilience in SGM offspring (Butauski \& Horstman, 2018; Doty et al., 2010; Mena \& Vaccaro, 2013). This is important because it may take time for parents to show support of their child's SGM identity (Grafsky, 2014; Tyler, 2015) and some fail to grow to show support of their child's SGM identity (Muller, 1987). Parents may not provide initial support of their child's SGM identity, but they can grow to affirm and commend their child's identity. In doing so, parents can create a healthy communication environment characterized by low levels of CPCA in which their SGM offspring feel safe and comfortable interacting with them.

Although these parent-child relationships are characterized by inherent intergroup dynamics, intragroup dynamics in the relationship persist. For example, in everyday conversation, intergroup dynamics in the parent-child relationship may not be salient. These identity differences may only become salient to their interactions when discussing information 
relative to their divergent values and identity differences. Perhaps the average amount of time since SGM children's coming out plays an important role in intra- versus intergroup dynamics in these parent-child relationships. Similarly, it is important to consider that in some SGM adult children's parent-child relationships, SGM identities and subsequent values may not spark intergroup salience in the ways one might expect. For example, some parents show support of their child's SGM identity upon their coming out by expressing indifference (Butauski \& Horstman, 2018). In other words, some parents view their child's coming out as a nonissue or nonevent. These relationships may lack intergroup salience, making accommodative communication less important to the parent-child communication environment and the child's mental health.

Identity support in intergroup family relationships can be essential to fostering relational quality and solidarity and minimizing intergroup salience (Colaner et al., 2014; Soliz et al., 2009; Soliz \& Rittenour, 2012). Intergroup family relationships can be characterized by a variety of differences, such as differences in religious beliefs or race/ethnicity. This study highlights how identity support and respect for divergent values relate to important mental health outcomes (i.e., depression) through creating a supportive communication climate. Past research has focused on how accommodative communication relates to relationship quality and solidarity. For example, Colaner et al. (2014) found that parent's respect for their child's divergent religious values was positively associated with their child's relationship satisfaction and feelings of shared family identity. Similarly, Soliz et al. (2009) found that parents' and grandparents' support of offspring's multiracial/ethnic identities positively contributed to relational solidarity. Further, their support of offspring's multiracial/ethnic identities helped minimize intergroup salience. The current study contributes to this body of literature by focusing on individual, rather than 
relational outcomes. Future research should consider both individual and relational outcomes as they relate to accommodative communication. As family relationships become increasingly diverse, it is important to recognize the value of communicating support for potentially divergent identities within family systems.

Findings of the current study support Pitts and Harwood's (2015) assertion that accommodative communication is competent communication because communication accommodation can facilitate identity, relational, and interactional goals. Parents' respect for divergent values and SGM identity support demonstrates their adaptability to changes in the parent-child relationship prompted by a child's coming out, as well as decreases their SGM child's CPCA. People who are competent communicators consider a variety of factors, such as context, social norms, and, perhaps most importantly, the characteristics of the individuals with whom they are speaking (Pitts \& Harwood, 2015; Spitzberg, 1983). This demonstrates how communication accommodation reflects competent communication used to create supportive communication climates between interlocutors. In this context, parents' accommodative communication demonstrates their willingness to adapt their behaviors to communicate effectively and appropriately to best meet the needs of their child and the parent-child relationship (Pitts \& Giles, 2008), as well as illustrates parents' accommodation competence because they are communicating in ways that meet the needs of their relational context (Pitts \& Harwood, 2015). In doing so, parents foster a supportive, open parent-child communication environment for their SGM children (Oswald, 2002; Soliz et al., 2010).

In communicating support and respect for divergent values in close intergroup relationships, interlocutors showcase a relational approach to communication competence, which allows them to "achieve goals in a prosocial fashion" (Spitzberg \& Cupach, 1984, p. 68). When 
relational partners are considerate of their partner's goals, they are perceived to be more competent communicators (Lakey \& Canary, 2002). At the core of communication competence is the concern for achieving goals through communication. In the context of SGM adult children's parent-child relationships, parents' end goal might be that their children no longer identify as SGM individuals and they may communicate in ways to try to reach that goal. In these cases, their communication would likely not be perceived as competent. These parents would likely not be accommodating in their communication or willing to meet the needs of their SGM child because they would be communicating in ways to meet their own goal. Thus, it is important to consider that some parents may not have the capacity to put their children's needs first and communicate in ways that are accommodating to their children.

Future directions: Intergroup parent-child relationships. Although the current study brings important attention to intergroup dynamics in SGM adult children's parent-child relationships, the intergroup nature of these parent-child relationships deserves further inquiry. Intergroup communication is "complex and messy, with many elements dynamically intertwined as individuals negotiate their group identities," (Gallois et al., 2018, p. 310). There are intergroup differences in these relationships based different values regarding gender and sexuality (Soliz et al., 2010), religion, politics, and education (Butauski, 2018b; Newman \& Mizzonigro, 1993), and generational differences (Dunlap, 2014; Grierson \& Smith, 2005). Intergroup dynamics are multifaceted with a variety of factors that may contribute to intergroup salience in these parentchild relationships, and thus a variety of avenues for future research.

First, the multifaceted dynamics of intergroup communication in parent-child and family relationships are likely especially salient to SGM people of color. Cultural considerations play especially important confounding factors to ethnic and racial minorities' coming out experiences 
and the navigation of their family relationships (Bie \& Tang, 2016; Bowleg et al., 2009; Harper et al., 2004). SGM people of color encounter a variety of challenges when coming out to their families based on their ethnic, cultural, and racial backgrounds (Savin-Williams, 1996; Merighi \& Grimes, 2000; Tremble, Schneider, \& Appathurai, 1989) and are less likely to be out to their parents at all (Grov, Bimbi, Nanin, \& Parsons, 2006). Cultural and religious traditions of people of color are often less open and accepting of SGM identities (Harper, Jernewall, \& Zea, 2004). As such, these values can make it more challenging for parents to accept their child's SGM identity because they must question deeply ingrained moral and spiritual values to positively adapt to their child's coming out. Further, because religious beliefs play an important role in parents' understanding of SGM identities, it is important to consider the experiences of SGM individuals with various religious backgrounds.

Various cultural and religious traditions often adhere to heteronormative conceptions of sexuality and gender. Consequently, people of color are often less inclined to come out to their parents as well as less open about their SGM identity in general for fear of bringing shame upon their families (Bie \& Tang, 2016; Grov et al., 2006; Harper et al., 2004). For example, Bowleg, Burkholder, Teti, and Craig (2009) found that black lesbian and bisexual women's familial, community, and religious concerns often outweighed their individualistic need to be out. An important limitation to the current study is the lack of racial diversity in the sample. This may be because to participate, respondents had to be out to their parents (Grov et al., 2006). Because research has shown that people of color are less likely to be out to their parents, it is important for future research to examine their parent-child relationships.

Similarly, traditional Chinese cultural values regarding family, marriage, and duty play a major role in shaping Chinese gay men's coming out, oftentimes making it more difficult for 
parents to adjust to their coming out (Bie \& Tang, 2016). Thus, it is important for future research to also consider the parent-child relationships of SGM individuals with parents who immigrated from countries where traditional values surrounding gender and sexuality are privileged. It is also important for future research to consider examining the parent-child relationships of SGM individuals outside of the United States, particularly in countries where SGM identities are highly stigmatized. Intergroup salience may be exasperated in these contexts and in parent-child relationships in which parents adhere to more traditional family values and SGM children diverge from these values (Newman \& Muzzonigro, 1993).

In the same vein, it is imperative that scholars consider both sides of the relationship when divergent identities and values are present. Put differently, it is important that all identities within close intergroup relationships are respected and supported. In cases where parents may have deeply held values contributing to negative perceptions of or lack of support for their children's SGM identity, it is still important that both the parents' and the children's social identities, beliefs, and values are respected by one another. In these relationships, functional topic avoidance may help amplify the intragroup dynamics of parent-child relationships. In other words, topic avoidance may be functional in these relationships such that it may allow parents and children to avoid discussing topics that could bring intergroup salience to the forefront. Functional topic avoidance can be accommodating in these situations as it promotes intragroup dynamics. Future research should consider the role of functional topic avoidance as accommodating communication and investigate how all social identities present in close intergroup relationships can be sustained and supported. 
Overall, it is important to recognize the intersectional nature of SGM identity and culture as it relates to the intergroup dynamics of parent-child and other family relationships. Future studies should aim to identify the characteristics contributing to intergroup salience in these contexts to gain a better understanding of how communication accommodation may best serve these relationships.

\section{Communication Apprehension in Close Intergroup Relationships}

The current study brings attention to how accommodative communication relates to CPCA and features communication apprehension as an important consideration in close intergroup relationships. Previous research has pinpointed a variety of factors that may contribute to CPCA in the parent-child relationship such as insecure attachments (Critchfield \& Benjamin, 2008), experiences of alienation, and previous negative interactions (Aloia \& Strutzenburg, 2019). The current study built upon this scholarship by using CAT as the guiding theory to investigate how communication accommodation are negatively related to CPCA. SGM adult children's perceptions of their parents' accommodative communication behaviors - respect for divergent values and SGM identity support - were significantly related to lower levels of SGM adult children's CPCA. This is important because CPCA undermines parent-child relational quality and deters children from openly communicating with or seeking advice from their parents (Cascio et al., 2013; Luchetti et al., 2002). Thus, experiencing communication apprehension - or feelings of fear or anxiety towards anticipated or actual communication could inhibit individuals' abilities to overcome intergroup differences in close relationships.

Because communication apprehension focuses specifically on the negative feelings one has toward anticipated or actual communication with a specific person or in a specific context (Luchetti et al., 2002), it serves as a better indicator of intergroup dynamics in close relationships 
than intergroup anxiety. Previous research has focused on communication accommodation as it relates to intergroup anxiety, or the awkward and uneasy feelings that occur during intergroup interactions (Soliz et al., 2010). Although intergroup anxiety has been assessed in intergroup family relationships (Soliz et al., 2010), it is mostly used in investigations of intergroup communication between strangers (Pettigrew et al., 2011). Conceptually, intergroup anxiety is defined as the uneasiness or awkwardness felt during interaction and is most often assessed regarding one's interactions with a stranger with a specific outgroup identity (Pettigrew et al., 2011). When assessing intergroup anxiety, respondents are asked to identify how awkward and self-conscious as well as how happy and relaxed they feel during conversations with outgroup members (Soliz et al., 2010; Voci \& Hewstone, 2003).

On the other hand, communication apprehension references fear towards real or anticipated communication with a specific target or within a specific context. Assessments of communication apprehension target specific feelings about specific communication behaviors, rather than just feelings experienced during an intergroup interaction. For example, items in Luchetti et al.'s (2002) CPCA scale include statements such as “I feel strained when anticipating talks with my parent" and "I'm afraid to come right out and tell my parent what I mean." As such, assessing one's communication apprehension in close intergroup relationships, such as SGM adult children's relationship with their non-SGM parents, provides a greater understanding of the communication dynamics of the relationships. Research guided by CAT may be better served by examining how accommodative and nonaccommodative communication behaviors influence CPCA because CPCA may be a better indicator of individuals' (lack of) willingness to communicate in ways that can minimize intergroup salience. 
Assessing communication apprehension in close intergroup relationships is important because communication apprehension is often characteristic of precarious relationships (Aloia \& Strutzenburg, 2019). In the context of close intergroup relationships, communication apprehension suggests that intergroup barriers in the relationship are pervasive. Communication apprehension, like intergroup anxiety, may inhibit relational partners' abilities to overcome intergroup differences. In other words, communication apprehension in close intergroup relationships may obstruct relational partners' willingness to address and overcome intergroup differences because they feel uneasy towards communicating. On the other hand, CPCA may be indicative of functional topic avoidance that allows intergroup relational partners to avoid conflict. Healthy balances between openness and closedness of communication can foster relationship satisfaction (Caughlin \& Afifi, 2004). Although topic avoidance is often negatively related to relationship satisfaction, it has positive functions that can protect social bonds (Afifi \& Guerrero, 2000; Caughlin \& Afifi, 2004; Caughlin \& Petronio, 2004).

Experiencing communication apprehension in close relationships can deter relational partners from openly communicating with and seeking support from one another (Cascio et al., 2013; Luchetti et al., 2002). Because communication apprehension can threaten relationship quality and inhibit interlocutors from engaging in open communication, communication apprehension could be especially detrimental to close intergroup relationships. Thus, it is imperative for future scholars to continue investigating the role of communication apprehension in close intergroup family relationships and continue investigating the role of communication accommodation in reducing communication apprehension.

Overall, findings of the current study highlight the positive role of communication accommodation in reducing communication apprehension in SGM adult children's intergroup 
parent-child relationships, as well as highlights communication apprehension as an important consideration in close intergroup relationships. In addition, the current study provides important insights on how SGM adult children's parent-child communication relates to their mental health.

\section{Parent-child Communication and SGM Adult Children's Mental Health}

In general, research consistently evidences that SGM individuals have heightened vulnerabilities to mental health problems, suicidal ideation, suicide attempts, and substance abuse (Baiocco et al., 2015; Ryan et al., 2010; James et al., 2016; Medley et al., 2016; Salway Hottes et al., 2016) and are more likely than their heterosexual, cisgender counterparts to experience a mental health condition (James et al., 2016; Medley et al., 2016; Salway Hottes et al., 2016). On average, participants in the current study experienced similar rates of depression $(M=2.09, S D=0.80)$ and anxiety $(M=2.20, S D=0.85)$. This makes sense, given that research shows that symptoms of anxiety often coincide with depressive symptoms and vice versa and that many individuals diagnosed with anxiety have secondary a depression diagnosis and vice versa (Stavrakaki \& Vargo, 1986). Furthermore, chronic states of anxiety often involve the development of depressive symptoms (Hays, 1964; Stavrakaki \& Vargo, 1986).

Findings suggest that parent-child relationship dynamics may play a more significant role in SGM adult children's depressive symptoms in comparison to their symptoms of anxiety. The central component of depressive symptoms is negative affect (e.g., feelings of hopelessness), whereas the central component of anxiety is excessive worrying (Nitschke, Heller, Imig, McDonald, \& Miller, 2001). Thus, it makes sense that parent-child relationship dynamics play a bigger role in SGM adult children's depressive symptoms in comparison to their anxiety. They are likely experiencing chronic negative affect toward their parent-child relationship, which would best explain why their parent-child communication is more strongly associated with 
depressive symptoms rather than symptoms of anxiety. Furthermore, SGM adult children's anxiety could be attributed to factors outside the parent-child relationship, such as experiences of discrimination or harassment (Evans \& D'Augellie, 1996; Woodford et al., 2014).

Findings of the current study provide a deeper understanding of SGM individuals' relationships with their parents by focusing on perceptions of specific communication behaviors within the parent-child relationship as it relates to their mental health. Preliminary analyses further evidence the importance of supportive, affirming parent-child relationships to SGM offspring's mental health (Baiocco et al., 2015; Mena \& Vaccaro, 2013; Reeves et al., 2010; Ryan et al., 2010). Preliminary bivariate correlational analyses indicated a negative relationship between parents' respect for divergent values and SGM adult children's depression and anxiety and a strong positive relationship between SGM adult children's CPCA and their depression and anxiety. However, there was not a significant relationship between parents' SGM identity support and SGM adult children's mental health, as hypothesized. The child's SGM identity may become less salient to SGM adult children and the relationship dynamics as parent-child relationships positively adjust after a child's initial coming out (Tyler, 2015). In other words, as parents positively adapt to their child's coming out and the parent-child relationship recalibrates over time, the intergroup barriers based on the child's SGM identity likely dissipate. This allows intergroup salience to fall to the wayside and interpersonal salience to rise to the forefront as the relationship recalibrates or improves. Overall, preliminary findings suggest that, beyond the initial coming out event, parent-child communication is paramount to creating a supportive communication climate and fostering more positive mental health outcomes.

Hypothesis-testing (through SEM) demonstrated that SGM identity support and respect for divergent values from parents did not directly relate to SGM adult children's depression and 
anxiety as hypothesized. This could be due to a lack of statistical power. Although parents' accommodative communication was not directly related to SGM adult children's mental health, these accommodative communication behaviors fostered a more supportive communication environment, which positively contributes to SGM adult children's mental health. Specifically, SEM analyses showed that CPCA was approaching significance as a mediator of the relationship between parents' respect for divergent values and SGM adult children's depression $(\beta=-0.14, p$ $=.07$ ) and CPCA was significantly associated with depression. These findings underscore how affirming parent-child communication positively contributes to SGM adult children's mental health. Parents' accommodative communication behaviors highlight parents' resilience in their efforts to show support and respect for their child. These accommodative communication behaviors underscore parents' responsiveness and attentiveness to their child's needs, which can cultivate their child's resilience (Theiss, 2018), which helps protect SGM individuals from negative mental health outcomes (Asakura, 2016).

The current study also sheds light on how the intergroup dynamics of SGM adult children's parent-child relationships relate to important mental health outcomes, in particular. Past intergroup family research guided by CAT has mainly focused the relational outcomes of accommodative communication - such as relational quality and feelings of shared family identity - as well as how communication accommodation can foster more positive perceptions of outgroup members (Colaner et al., 2014; Soliz, 2007; Soliz \& Rittenour, 2012). In the current study, accommodative communication behaviors related to SGM offspring's mental health. This is notable as many SGM individuals are navigating precarious and, at times, unsupportive family relationships beyond their initial coming out (Bie \& Tang, 2016; Butauski, 2018b; Nuru, 2014). 
Findings regarding SGM individuals' mental health also underscore the negative implications of experiencing CPCA. CPCA is often indicative of a particularly distressing and precarious parent-child relationship in which anticipating or engaging in parent-child communication is uncomfortable and anxiety-inducing for offspring (Aloia \& Strutzenburg, 2019; Butauski, 2018b). Another way to make sense of the link between CPCA and depression is through the communication theory of identity (CTI). CTI emphasizes the communicative nature of identity and outlines four frames of identity (personal, relational, enacted, and communal) that can be in tension with one another, leading to the experience of identity gaps (Jung, 2013). When these frames are inconsistent or in tension with one another, identity gaps emerge. Jung (2013) found that communication apprehension was strongly associated with the experience personalrelational, personal-enacted, and enacted-relational identity gaps. In turn, these identity gaps were significantly associated with depressive symptoms. Because identity management is a prevalent stressor in SGM individuals' experiences (Asakura, 2016; Sanlo, 2004) and communication apprehension is strongly associated with the experience of identity gaps, SGM adult children's experiences of CPCA may coincide with experiences of identity gaps. This may further explain the association between CPCA and depression among SGM adult children, as identity gaps are associated with depressive symptoms (Jung, 2013).

Overall, findings shed light on communication behaviors in SGM adult children's parentchild relationships as they relate to SGM adult children's mental health. Parents' support and acceptance of their child's identity protects against suicidal behaviors, promotes positive mental health outcomes, and reinforces positive senses of self (Eisenberg \& Resnick, 2006; Ryan et al., 2010; Savin-Williams, 1989). These positive contributions to SGM individuals' mental health and senses of self foster their resilience, which enhances their abilities to overcome minority 
stress and mental health issues like depression and anxiety (Asakura, 2016). Researchers should continue working to identify communication behaviors in this relationship that contribute to SGM offspring's mental health and resilience. In doing so, the current study serves as a springboard for future research on fostering positive mental health outcomes and resilience among SGM individuals.

Future directions: Fostering resilience. As researchers continue to investigate the role of communication in parent-child relationships in SGM offspring's well-being, it is imperative to focus on parent-child communication beyond the initial coming out event. Researchers should continue working to identify communication behaviors in this relationship that contribute to SGM offspring's mental health and resilience. Building upon this line of research, it is important to consider how parents' nonaccommodative communication behaviors are detrimental to personal and relational outcomes in SGM offspring's parent-child relationships. Parents' nonaccommodative communication behaviors demonstrate a failure to adapt to their communication behaviors to meet their child's needs. Nonaccommodative communication emphasizes intergroup differences and can involve using aggressive or argumentative behaviors (Mikkelson \& Hesse, 2009). This may involve saying unsupportive or hurtful things to their child, which could lead to negative reflected appraisals (Savin-Williams, 1989), and in turn, CPCA and negative mental health outcomes. In other words, parents' nonaccommodative communication may be deleterious to SGM offspring's sense of self, mental health, and overall well-being. Thus, it is imperative that future research considers the role of nonaccommodative communication behaviors in SGM offspring's parent-child relationships.

Further, it is imperative to do longitudinal research to examine how the parent-child relationship adapts and/or changes upon a child's initial coming out. In constructing longitudinal 
research to examine this relationship, it is important for researchers to pinpoint how both parents' and children's communication may foster or hinder relationship recalibration and SGM offspring's mental health beyond the initial coming out event. Even when parents initially react positively to their child's coming out, they still may struggle with positively adapting to their child's revelation as they process the disclosure and what it might mean for their child's future (i.e., facing discrimination) (Butauski \& Horstman, 2018; Grafsky, 2014). As such, how accommodating parents are in their communication with their child may fluctuate over time from the initial coming out event as parents work to make sense of and support their child's SGM identity. This further highlights the need to understand both the accommodative and nonaccommodative communication behaviors in the parent-child relationship that may help or hinder relationship recalibration and contribute to SGM offspring's mental health. Longitudinal research starting shortly after a child's coming out would best capture how the relationship adjusts and recalibrates over time after the initial coming out event.

Finally, little is known about how parent-child relationships adapt after a gender minority identity is disclosed. Coming out as transgender or nonbinary can be much more complex than coming out as lesbian or gay because these gender minorities often must come out before and after changing their expressions of gender (Zimman, 2009). It is likely that it may be more difficult or tasking for parent-child relationships to recalibrate and/or improve after a gender minority identity is revealed. Grieving the pre-coming out identity and adapting to the revealed gender identity can be extremely complex, challenging, and overwhelming (Grossman, \& D’Augelli, 2006; Nuru, 2014). Thus, parents may find it more difficult to communicate respect and support for, as well as positively adapt to, gender minority identities. Because gender minorities are extremely vulnerable to depression, suicidal ideation, and making suicide attempts 
(James et al., 2016), it is imperative that researchers aim to gain a deeper understanding of their experiences. Future research should focus specifically on gender minority individuals' relationships with their parents to gain a deeper understanding of how they navigate their parentchild relationships after coming out and after changing their gender expressions. The dynamics of their parent-child relationships likely have important implications for gender minority individuals' mental health and resilience, which fosters their ability to deal with minority stress.

\section{Limitations}

Although the current study helps provide a deeper understanding of SGM individuals' parent-child relationships, the investigation has notable limitations. First, the sample lacks ethnic and racial diversity. Research shows that coming out and navigating parent-child relationships can be much more challenging for people of color (Grov et al., 2006; Harper et al., 2004;

Merighi \& Grimes, 2000). However, the lack of racial diversity among the sample may be due to the inclusion criteria of the study, which required participants to be out to their parents. Future research should purposefully sample an ethnically and racially diverse sample to gain a deeper understanding of the experiences of SGM people of color, regardless of whether they are out to their parents and families.

The goal of the current study was to investigate parent-child relationships beyond the initial coming out event. In doing so, this excluded SGM individuals who were not out to their parents from participating in the study. Because closeting one's SGM identity and being unable to enact one's authentic self can be extremely distressing (Butauski, 2018b; Nuru, 2014; SavinWilliams, 2001, 2005), it is imperative to gain a deeper understanding of how SGM individuals who are not out to their parents and families navigate these relationships. Scholars should 
investigate the parent-child relationship dynamics of SGM adults who are not out to their parents.

Another limitation to the study is the lack of gender representation in the sample. Although the current sample provided representation of a variety of sexual orientations, the sample mostly consisted of cisgender females (57.3\%) and 70 percent of the sample identified as cisgender. Critics might suggest that the inclusion of gender minority individuals in the current study is also a limitation, such that gender minority individuals have unique experiences relative to those with sexual minority identities (Zimman, 2009). However, it is important to note that all the participants who identified as a gender minority also identified as a sexual minority. Not including the individuals who identified a gender minority identity would have erased the experiences of 30 percent of the current sample. As the SGM community becomes increasingly diverse, it is important to consider the multifaceted identities of SGM individuals. Future research should consider the role of having multiple marginalized identities, such as having a sexual, gender, and racial minority identity.

Additionally, the current study only considers the perspectives of SGM adult children. Scholars are only beginning to gain an understanding of the experiences of parents' SGM adult children and more research is needed to more fully grasp parents' experiences. Research that has investigated parents' perspectives emphasizes personal transformations of parents in positively adapting to their child's SGM identity (Butauski \& Horstman, 2018; Gonzalez et al., 2013; Grafsky, 2014; Saltzburg, 2004, 2009). However, less is known about the experiences of parents who do not positively adapt to their child's revelation. Future research should continue investigating parents' perspectives, especially those who are not as supportive of their child's SGM identity. 
Finally, the current study is cross-sectional and only considers the role of parent-child relationships in relation to SGM adult children's mental health, which makes the scope of the study limited. Although research consistently evidences the importance of supportive parentchild relationships to the mental health of SGM individuals, positive parent-child and family relationships are not always available to the SGM community. Thus, it is imperative that researchers investigate how SGM individuals can foster resilience when their family-of-origin relationships are not supportive or are estranged.

In the same vein, it is imperative to look beyond parent-child and family relationships as there are other outlets of support critical to SGM individuals' mental health (Asakura, 2016). Parental and family support promote more positive mental health outcomes among SGM individuals (Eisenberg \& Resnick, 2006; Ryan et al., 2010). However, research has identified a variety of meaningful sources of resilience for SGM individuals outside their families of origin. For example, Asakura (2016) found that SGM youth cultivate resilience through seeking and maintaining meaningful relationships and asserting their personal agency to make decisions (e.g., leaving their church, transitioning their gender, leaving or staying home following a family rejection) (Asakura, 2016). Because supportive, affirming relationships are central to their wellbeing, and families of origin are not always supportive and affirming, future research should consider how the communication in close relationships outside of the family of origin foster resilience and well-being among SGM individuals.

\section{Practical Applications}

There are important practical implications to the findings of the current study. First, SGM individuals' parent-child relationships are central to their mental health, well-being, and resilience (Mena \& Vaccaro, 2013; Ryan et al., 2010; Savin-Williams, 1989), but parents often 
take time to positively adjust to their child's SGM identity. Thus, it is also essential for SGM offspring to work to create supportive communication environments with their parents to foster their parents' understanding of their SGM identities. Because children's coming out may bring intergroup barriers to the forefront of parent-child relationships, it is also valuable for children to communicate in ways that acknowledge parents' perspectives and potentially negative feelings towards SGM identities. Doing so may help parents more positively make sense of and adjust to their child's identity. For example, when SGM offspring engaged in communicated perspective taking $(\mathrm{CPT})$ - or the process of acknowledging and confirming another's point of view - during their coming out to their parents, parents were more likely to express support of their child's SGM identity and have positive affect towards their child's coming out (Butauski \& Horstman, 2018). Engaging in CPT when coming out to parents and discussing one's SGM identity is helpful to parents, yet it is important to recognize that engaging in CPT can be tolling (Horstman et al., 2016). Although it may be tolling, it could be essential in helping parents grow to understand their SGM identity and ameliorating intergroup salience.

Second, these findings can inform practitioners' work with parents of SGM children, as well as support groups parents turn to after a child comes out through organizations such as Parents and Friends of Lesbians and Gays (PFLAG). Although it is important for parents to learn how to grasp and understand their child's SGM identity, it is also vital for them to learn how to communicate in ways that show support and respect of their child's identity and values, even as they work through positively adjusting to their child's coming out. PFLAG support groups help parents learn more about their child's identity and how to positively adjust to their child's identity. Because appropriate, effective, and accommodating communication (i.e., competent communication) is a learned skill (Pitts \& Harwood, 2015), parents would benefit from learning 
about how to communicate in ways that show respect for their child's divergent values and support for their child's SGM identity. Showing respect does not necessarily mean that parents agree with their child, but does communicate acknowledgement and commendation of their child's autonomy. Practitioners and support group leaders can explain how these accommodative communication behaviors will help parents create a supportive communication environment with their SGM children that promote more open communication and more positive mental health outcomes for their children.

SGM individuals and their parents would both greatly benefit from educational programming and interventions that aim to develop the communication skills necessary to take the perspective of one another and engage in accommodating communication. In doing so, parents and SGM children can learn how to better meet the needs of one another and the relationship. This can foster relationship recalibration and understanding. Such interventions and programming might also be beneficial to parent-child relationships at large. Many parent-child relationships can be characterized by a variety of intergroup barriers such as difference in religion, race/ethnicity, or age. Thus, parents and children overall might benefit from learning how to better communicate with one another. This could help parents and children overcome a variety of intergroup barriers.

Finally, SGM individuals should seek affirming, supportive relationships with others, especially when parental support is lacking or unavailable (Asakura, 2016). Cultivating relationships with people who are affirming and supportive and other SGM individuals fosters SGM individuals' resilience. These relationships are essential to the well-being of individuals who have been rejected by their families of origin as they provide "corrective relational experiences" (Asakura, 2016, p. 28). When support is lacking or unavailable, it is crucial for 
SGM individuals to create and maintain supportive and affirming social ties. This social support enhances SGM individuals' abilities to cope with minority stress (Asakura, 2016).

\section{Conclusion}

In sum, the current study sheds light on SGM adult children's parent-child relationships beyond their initial coming out from an intergroup perspective. Findings highlight the importance parents using accommodative communication to create a supportive communication climate with their children to promote more positive mental health outcomes. Although perceptions of parents' accommodative communication behaviors were not directly related to SGM adult children's mental health, experiencing higher rates of CPCA was directly related to higher rates of depression and accommodative communication helps reduce CPCA. Overall, the current study serves as a springboard for important scholarship continuing to investigate the intergroup nature of these parent-child relationships and ways to promote resilience in this vulnerable population. 


\section{References}

Aloia, L. S. \& Strutzenberg, C. (2019) Parent-child communication apprehension: The role of parental alienation and self-esteem. Communication Reports, 32(1), 1-14. doi:10.1080/08934215.2018.1514641

Arnett, J. J. (2000). Emerging adulthood a theory of development from the late teens through the twenties. American Psychologist, 55, 469-480. doi:10.1037//0003-066X.55.5.469

Asakura, K. (2016). Extraordinary acts to "show up": Conceptualizing resilience of LGBTQ youth. Youth and Society, 51(2), 1-8. doi:10.1177/0044118X16671430.

Asakura, K., \& Craig, S. L. (2014). “It gets better”...but how? Exploring resilience development in the accounts of LGBTQ adults. Journal of Human Behaviors in the Social Environment, 24, 253-266. doi:10.1080/10911359.2013.808971

Baiocco, R., Fontanesi, L., Santamaria, F., Ioverno, S., Marasco, B., Baumgartner, E., Willoughby, B. L. B., \& Laghi, F. (2015). Negative parental responses to coming out and family functioning in a sample of lesbian and gay young adults. Journal of Child and Family Studies, 24, 1490-1500. doi:10.1007/s10826-014-9954-z

Baptist, J. A., \& Allen, K. R. (2008). A family’s coming out process: Systematic change and multiple realities. Contemporary Family Therapy, 30, 92-110 doi:10.1007/s10591-0089057-3

Bariola, E., Lyons, A., Leonard, W., Pitts, M., Badcock, P., Couch, M. (2015). Demographic and psychosocial factors associated with psychological distress and resilience among transgender individuals. American Journal of Public Health, 105, 2108 - 2118. 
Beatty, M. J., \& Dobos, J. A. (1992). Adult sons' satisfaction with their relationships with fathers and person-group (father) communication apprehension. Communication Quarterly, $40(2), 162-176$.

Biblarz, T. J. \& Savci, E. (2010). Lesbian, gay, bisexual, and transgender families. Journal of Marriage and Family, 72, 480-197. doi:10.1111/j.1741-3737.2010.00714.x

Bowleg, L., Burkholder, G., Teti, M., \& Craig, M. L. (2009). The complexities of outness: Psychosocial predictors of coming out to others among black lesbian and bisexual women. Journal of LGBT Health Research, 4(4), 153-166. doi:10.1080/15574090903167422

Burleson, B. R., \& MacGeorge, E. L. (2002). Supportive communication. In M. L. Knapp \& J. A. Daly (Eds.), Handbook of interpersonal communication (pp. 374-424). Thousand Oaks, CA: Sage.

Butauski, M. (2018a). Emerging adults’ parent-child privacy management surrounding topics of career, religion, and politics. Iowa State Communication Journal, 50(1), 4-25.

Butauski, M. (2018b). Exploring LGBTQ adults' communication privacy management in navigating intergroup family relationships. Unpublished manuscript.

Butauski, M. \& Horstman, H. (2018). Parents' communicated narrative sense-making about their child's coming out: Investigating contributions of communicated perspective-taking and relational satisfaction. Paper presentation at the annual meeting of the National Communication Association, Salt Lake City, UT. * Top paper of the Family Communication Division.

Buzzanell, P. (2010). Resilience: Talking, resisting, and imaging new normalcies into being. Journal of Communication, 60, 1-14. doi:10.1111/j.1460-2466.2010.01469.x 
Cascio, V. L., Guzzo, G., Pace, F., \& Pace, U. (2013). Anxiety and self-esteem as mediators of the relation between family communication and indecisiveness in adolescence. International Journal for Educational and Vocational Guidance, 13, 135-149. doi:10.1007/s10775-013-9243-1

Caughlin, J. P., \& Petronio, S. (2004). Privacy in families. In A. L. Vangelisti (Ed.), Handbook offamily communication (pp. 379-412). Mahwah, NJ: Erlbaum.

Colaner, C. W., Soliz, J., \& Nelson, L. R. (2014). Communicatively managing religious identity difference in parent-child relationships: The role of accommodative and nonaccommodative communication. Journal of Family Communication, 14(4), 310-327. doi:10.1080/15267431.2014.945700

Conley, C.L. (2011). Learning about a child's gay or lesbian orientation: Parental concerns about societal rejection, loss of loved ones, and child well-being. The Journal of Homosexuality, 58(5), 1022-1040. doi:10.1080/00918369.2011.59840.

Coupland, J., Coupland, N., Giles, H., \& Henwood, K. (1988). Accommodating the elderly: Invoking and extending theory. Language in Society, 17, 1-41. doi:10.1017/S00470400012574

Craig, S. L., McInroy, L., McCready, L. T., \& Alaggia, R. (2015). Media: A catalyst for resilience in lesbian, gay, bisexual, transgender, and queer youth. Journal of LGBT Youth, 12, 254-275. doi:10.1080/19361653.2015.1040193

Cramer, D. W. \& Roach, A. J. (1988). Coming out to mom and dad: A study of gay males and their relationships with their parents. Journal of Homosexuality, 15, 79-91.

Critchfield, K. L., \& Benjamin, L. S. (2008). Internalized representations of early interpersonal 
experience and adult relationships: A test of copy process theory in clinical and nonclinical settings. Psychiatry: Interpersonal and Biological Processes, 71, 71-92. doi:10.1521/psyc.2008.71.1.71

Cupach, W.R. \& Spitzberg, B.H. (1983). Trait versus state: a comparison of dispositional and situational measures of interpersonal communication competence. Western Journal of Speech Communication, 47(4), 364-379. doi:10.1080/10570318309374131

Currie, S., Mayberry, M., \& Chenneville, T. (2012). Destabilizing anti-gay environments through gay-straight alliances: Possibilities and limitations through shifting discourses. Clearing House, 85, 56-60. doi:10.1080/00098655.2011.611190

De Cremer, D., \& Tyler, T. R. (2005). A matter of intragroup status: The importance of respect for the viability of groups. In M. Thomas-Hunt (Ed.), Status and Groups (Vol. 7, pp. 123). Boston, MA: Emerald Group Publishing.

Dietvorst, E., Hiemstra, M., Hillegers, M. H. J., \& Keijsers, L. (2017). Adolescent perceptions of parental privacy invasion and adolescent secrecy: An illustration of Simpson's Paradox. Child Development, 00, 1-10. doi:10.1111/cdev.13002

Doty, N. D., Willoughby, B. L. B., Lindahl, K. M., \& Malik, N. M. (2010). Sexuality related social support among lesbian, gay, and bisexual youth. Journal of Youth and Adolescence, 39, 1134-1147.

Duncan, D. T., Hatzenbuehler, M. L., \& Johnson, R. M. (2014). Neighborhood-level LGBT hate crimes and current illicit drug use among sexual minority youth. Drug and Alcohol Dependence, 135, 65-70.

Dunlap, A. (2014). Coming-out narratives across generations. Journal of Gay \& Lesbian Social Services, 26, 318-335. doi:10.1080/10538720.2014.924460 
Dziengel, L. (2015). A be/coming out model: assessing factors of resilience and ambiguity. Journal of Gay \& Lesbian Social Services, 27(3), 302-325. doi:0.1080/10538720.2015.1053656.

Eisenberg, M. E., \& Resnick, M. D. (2006). Suicidality among gay, lesbian, and bisexual youth: The role of protective factors. Journal of Adolescent Health, 39, 662 - 668.

Fitzpatrick, M. A., \& Vangelisti, A. L. (1995). Explaining family interactions. Thousand Oaks, CA: Sage.

Gallois, C., Watson, B. M., \& Giles, H. (2018). Intergroup communication: Identities and effective interactions. Journal of Communication, 68, 309-317. doi:10.1093/joc/jqx016

Giles, H. \& Soliz, J. (2015). Communication accommodation theory a situated framework for relational, family, and intergroup dynamics. In D. O Braithwaite and P. Schrodt (Eds.), Engaging Theories in Interpersonal Communication Multiple Perspectives (pp. 161-187). Thousand Oaks, CA: Sage.

Giles, H. (2014). Communication accommodation theory. In: Craig, R. (Ed.), International Encyclopedia of Communication Theory and Philosophy. Wiley/Blackwell, New York, NY.

Grafsky, E. L. (2014). Becoming the parent of a GLB son or daughter. Journal of GLBT Family Studies, 10, 36-57. doi:10.1080/1550428X.2014.857240

Grov, C., Bimbi, D. S., Nanin, J. E., \& Parsons, J. T. (2006). Race, ethnicity, gender, and generational factors associated with the coming-out process among gay, lesbian, and bisexual individuals. The Journal of Sex Research, 43(2), 115-121.

Gonzalez, K., Rostosky, S., Odom, R., \& Riggle, E. (2013). The positive aspects of being the parent of an LGBTQ child. Family Process, 52, 325-337. doi:10.1111/famp.12009 
Grierson, J., \& Smith, A. (2005). In from the outer: Generational differences incoming out and gay identity formation. Journal of Homosexuality, 50(1), 53-70. doi:10.1300/ J082v50n01_03

Grossman, A. H., \& D'Augelli, A. R. (2006). Transgender youth: Invisible and vulnerable. Journal of Homosexuality, 51(1), 111-128. doi:10.1300=J082v51n01_06

Grossman, A. H., \& D'Augelli, A. R. (2007). Transgender youth and life-threatening behaviors. Suicide \& Life-Threatening Behavior, 37, 527-537.

Harper, G. W., Jernewall, N., \& Zea, M. C. (2004). Giving voice to emerging science and theory for lesbian, gay, and bisexual people of color. Cultural Diversity and Ethnic Minority Psychology, 10(3), 187-199. doi:10.1037/1099-9809.10.3.187

Hartwell, E. E., Serovich, J. M., Grafsky, E. L., \& Kerr, Z. Y. (2012). Coming out of the dark: Content analysis of articles pertaining to gay, lesbian and bisexual issues in couple and family therapy journals. Journal of Marital and Family Therapy, 38, 227-243. doi:10.1111/j.1752-0606.2011.00274.x

Harwood, J. Communicative predictors of solidarity in the grandparent-grandchild relationship. Journal of Social and Personal Relationships, 17, 743-766. doi:10.1177/0265407500176003

Harwood, J., Giles, H., \& Palomares, N. A. (2008). Intergroup theory and communication processes. In J. Harwood \& H. Giles (Eds.), Intergroup Communication: Multiple Perspectives (pp. 1-20). New York: Peter Lang

Harwood, J., Raman, P., \& Hewstone, M. (2006). The family and communication dynamics of group salience. Journal of Family Communication, 6, 181-200. doi:10.1207/s15327698jfc0603_2 
Hays, P. (1964). Modes of onset of psychotic depression. British Medical Journal, 2, 779-784.

Hershberger, S., \& D’Augelli, A. R. (1995). The impact of victimization on the mental health and suicidality of lesbian, gay, and bisexual youth. Developmental Psychology, 31, 6574. doi:10.1037/0012-1649.31.1.65

Heatherington, L. \& Lavner, J. A. (2008). Coming to terms with coming out: Review and recommendations for family systems-focused research. Journal of Family Psychology, 22, 329-343. doi:10.1037/0893-3200.22.3.329

Hershberger, S. L., Pilkington, N. W., \& D’Augelli, A. R. (1997). Predictors of suicide attempts among gay, lesbian, and bisexual youth. Journal of Adolescent Resarch, 12, 477-497.

Horstman, H.K., Maliski, R., Hays, A., Cox, J., Enderle, A., \& Nelson, L. R. (2016). Unfolding narrative meaning over time: The contributions of mother-daughter conversations of difficulty on daughter narrative sense-making and well-being. Communication Monographs, 83, 326-348. doi:10.1080/03637751.2015.1068945

James, S. E., Herman, J. L., Rankin, S., Keisling, M., Mottet, L., \& Anafi, M. (2016). The Report of the 2015 U.S. Transgender Survey. Washington, DC: National Center for Transgender Equality. Retrieved from https://www.transequality.org/sites/default/files/docs/USTSFull-Report-FINAL.PDF

Jamnik, M. R. \& Lane, D. J. (2018). The use of Reddit as an inexpensive source for high-quality data. Practical Assessment, Research, and Evaluation, 22(5), 1-10. Retrieved from http://pareonline.net/pdf/v22n5.pdf

Jenkins, D. A., (2008). Changing family dynamics: A sibling comes out. Journal of GLBT Family Studies, 4, 1-16. doi:10.1080/15504280802084365 
Jones, S., \& Bodie, G. (2014). Supportive communication. In C. Berger (Ed.), Interpersonal communication (pp. 371-394). Germany: Walter de Gruyer.

Jung, E. (2011). Identity gap: Mediator between communication input and outcome variables. Communication Quarterly, 59, 315-338. doi: 10.1080/01463373.2011.583501

Jung, E. (2013). Delineation of a threefold relationship among communication input variables, identity gaps, and depressive symptoms. Southern Communication Journal, 78(2), 163184. doi:10.1080/1041794X.2012.741652

Jung, E., \& Hecht, M. L. (2004). Elaborating the communication theory of identity: identity gaps and communication outcomes. Communication Quarterly, 52, 265-283.

Jung, E., \& Hecht, M. L. (2008). Identity gaps and level of depression among Korean immigrants. Health Communication, 23, 313-325. doi: 10.1080/10410230802229688

Kam, J. A., \& Hecht, M. L. (2009). Investigating the role of identity gaps among communicative and relational outcomes within the grandparent-grandchild relationship: The young-adult grandchildren's perspective. Western Journal of Communication, 73(4), 456-480. doi:10.1080/10570310903279067

Kline, R. B. (2005). Principle and practice of structural equation modeling. New York, NY: Guilford Press.

Kline, R. B. (2011). Principle and practice of Structural Equation Modeling ( $\left.3^{\text {rd }} \mathrm{ed}\right)$. New York, NY: The Guilford Press.

Kroenke, K., Spitzer, R. L., \& Williams, J. B. W. (2001). The PHQ-9 validity of a brief depression severity measure. Journal of General Internal Medicine, 16, 606-613. doi:10.1046/j.1525-1497.2001.016009606.x 
Kwon, P. (2013). Resilience in lesbian, gay, and bisexual individuals. Personality and Social Psychology Review, 17, 371 - 383. doi: 10.1177/1088868313490248

Lakey, S. G. \& Canary, D. J. (2002). Actor goal achievement and sensitivity to partner as critical factors in understanding interpersonal communication competence and conflict strategies. Communication Monographs, 69(3), 217-235. doi:10.1080/03637750216542

Little, T. D., Cunningham, W. A., Shahar, G., \& Widaman, K. F. (2002). To parcel or not to parcel: Exploring the question, weighing the merits. Structural Equation Modeling, 9, 151-173. doi:10.1207/S15328007SEM0902_1

Luchetti, A. E., Powers, W. G., \& Love, D. E. (2002). The empirical development of the childparent communication apprehension scale for use with young adults. Journal of Family Communication, 2(3), 109-131.

Lustig, M. W. \& Anderson, P. A. (1990). Generalizing about communication apprehension and avoidance: Multiple replications and meta-analyses. Journal of Social Behavior and Personality, 5(4),

Medley, G., Lipari, R. N., Bose, J., Cribb, D. S., Kroutil, L. A., \& McHenry, G. (2016). Sexual orientation and estimates of adult substance use and mental health: Results from the 2015 National Survey on Drug Use and Health. Retrieved April 2, 2018, from https://www.samhsa.gov/data/sites/default/files/NSDUH-SexualOrientation2015/NSDUH-SexualOrientation-2015/NSDUH-SexualOrientation-2015.htm

Maccoby, E. E.,\&Martin, J. (1983). Socialization in the context of the family: Parent-child interaction. In P. H. Mussen (Series Ed.) \& E.M. Hetherington (Vol. Ed.), Handbook of child psychology: Vol. 4. Socialization, personality, and social development (4th ed., pp. 1-101). New York: Wiley. 
McCroskey, J. C. (1984). The communication apprehension perspective. In J. A. Daly, \& J. C. McCroskey (Eds.), Avoiding communication: Shyness, reticence, and communication, (pp. 13-38). Beverly Hills, CA: SAGE Publications.

McCroskey, J. \& Richmond, V.P. (1977). Communication apprehension as a predictor of self-disclosure. Communication Quarterly, 25, 40-43. doi:10.1080/01463377709369271

McElroy, J. A., Wintemberg, J. J., Cronk, N. J., \& Everett, K. D. (2016). The association of resilience, perceived stress and predictors of depressive symptoms in sexual and gender minority youths and adults. Psychology \& Sexuality, 7, 116-130. doi:10.1080/19419899.2015.1076504

Mena, J. A., \& Vaccaro, A. (2013). Tell me you love me no matter what: Relationships and selfesteem. Journal of GLBT Family Studies, 9, 2-23. doi:10.1080/1550428X.2013.746052

Merighi, J. R., \& Grimes, M. D. (2000). Coming out to families in a multicultural context. Families in Society: The Journal of Contemporary Human Services, 81, 32-49.

Meyer, I. H. (1995). Minority stress and mental health in gay men. Journal of Health and Social Behavior, 36, 38-56. doi:10.2307/2137286

Meyer, I. H. (2003). Prejudice, social stress, and mental health in lesbian, gay, and bisexual populations: Conceptual issues and research evidence. Psychological Bulletin, 129(5), 674-697. doi:10.1037/0033-2909.129.5 Muller, A. (1987). Parents matter: Parents' relationships with lesbian daughters and gay sons. U.S.: Naiad Press.

Muller, A. (1987). Parents matter: Parents' relationships with lesbian daughters and gay sons. U.S.: Naiad Press.

Newman, B. S. \& Muzzonigro, P. G. (1993). The effects of traditional family values on the coming out process of gay male adolescents. Adolescence, 28, 213-226. 
Nitschke, J. B., Heller, W., Imig, J. C., McDonald, R. P., \& Miller, G. A. (2001). Distinguishing dimensions of anxiety and depression. Cognitive Therapy and Research, 25(1), 1-22. doi:10.1023/A:1026485530405

Nuru, A. K. (2014). Between layers: Understanding the communicative negotiation of conflicting identities by transgender individuals. Communication Studies, 65, 281297. doi:10.1080/10510974.2013.833527

Oswald, R. F. (2002). Resilience within the family networks of lesbians and gay men: Intentionality and redefinition. Journal of Marriage and Family, 64, 374-383.

Petronio, S. (2002). Boundaries of privacy: Dialectics of disclosure. Albany, NY: State University of New York Press.

Pettigrew, T. F., Tropp, L. R., Wagner, U., \& Christ, O. (2011). Recent advances in intergroup contact theory. International Journal of Intercultural Relations, 35(3), 271-280. doi:10.1016/j.ijintrel.2011.03.001

Potoczniak, D., Crosbie-Burnett, M., \& Saltzburg, N. (2009). Experiences regarding coming out to parents among African American, Hispanic, and white gay, lesbian, bisexual, transgender, and questioning adolescents. Journal of Gay \& Lesbian Social Services, 21, 189-205. doi: 10.1080/10538720902772063

Reeves, T., Horne, S. G., Rostosky, S. S., Riggle, E. D. B., Baggett, L. R., \& Aycock, R. A. (2010). Family members' support for GLBT issues: The role of family adaptability and cohesion. Journal of GLBT Family Studies, 6, 80-97 doi: 10.1080/15504280903472857

Reineke, J. (2009). The moral politics of censorship: Family communication patterns, political ideology, and support for censorship. Paper presentation at the annual meeting of the International Communication Association. 
Rittenour, C. E., \& Soliz, J. (2009). Communicative and relational dimensions of shared family identity and relational intentions in mother-in-law/daughter-in-law relationships:

Developing a conceptual model for mother-inlaw/daughter-in-law research. Western Journal of Communication, 73, 67-90. doi:10.1080/10570310802636334

Robinson, B. E., Walters, L. H., \& Skeen, P. (1989). Response of parents to learning that their child is homosexual and concern over AIDS: A national study. Journal of Homosexuality, 18, 59-80. doi:10.1300/J082v18n01_03

Rosenfeld, D., Bartlam, B., \& Smith, R. D. (2012). Out of the closet and into the trenches: Male baby boomers, aging, and HIV/AIDS. The Gerontologist, 52, 255-264. doi: $10.1093 /$ geront/gnr138

Rosseel, Y. (2012). lavaan: An R package for structural equation modeling. Journal of Statistical Software, 48, 1-36. Retrieved from: http://www.jstatsoft.org/v48/i02/

Ryan, C., Huebner, D., Diza, R. M., \& Sanchez, J. (2009). Family rejection as a predictor of negative health outcomes in white and Latino lesbian, gay, and bisexual young adults. Pediatrics, 123(1), 346-352.

Ryan, C., Russel, S. T., Huebner, D., Diaz, R., \& Sanchez, J. (2010). Family acceptance in adolescence and the health of LGBT young adults. Journal of Child and Adolescent Pyschiatric Nursing, 23, 205-2013. doi: 10.1111/j.1744-6171.2010.00246.x

Saewyc, E. M., Homma, Y., Skay, C. L., Bearinger, L. H., Resnick, M. D., \& Reis, E. (2009). Protective factors in the lives of bisexual adolescents in North America. American Journal of Public Health, 99, 110-117. doi:10.2105/AJPH.2007.123109

Saewyc, E. M., Konishi, C., Rose, H. A., \& Homma, Y. (2014). School-based strategies to reduce suicidal ideation, suicide attempts, and discrimination among sexual minority and 
heterosexual adolescents in western Canada. International Journal of Child, Youth and Family Studies, 5, 89-112.

Salway Hottes, T., Bogaert, L., Rhodes, A. R., Brennan, D. J., \& Gesink, D. (2016). Lifetime prevalence of suicide attempts among sexual minority adults by study sampling strategies: A systematic review and meta-analysis. American Journal of Public Health, 106(5), e1-e12. Retrieved from https://ajph.aphapublications.org/doi/pdf/10.2105/AJPH.2016.303088

Sanlo, R. (2004). Lesbian, gay, and bisexual college students: Risk, resiliency, and retention. Journal of College Student Retention, 6, 97-110.

Saltzburg, S. (2004). Learning that an adolescent is gay or lesbian: The parent experience. Social Work, 49, 109-118.

Saltzburg, S. (2009). Parents' experience of feeling socially supported as adolescents come out as lesbian and gay: A phenomenological study. Journal of Family Social Work, 12, 340-358 doi:10.1080/10522150903261932

Savin-Williams, R. C. (1989). Coming out to parents and self-esteem among gay and lesbian youths. Journal of Homosexuality, 18, 1-35.

Savin-Williams, R. C. (1996). Ethnic- and sexual-minority youth. In R. C. Savin-Williams \& K. M. Cohen (Eds.), The lives of lesbians, gays, and bisexuals: Children to adults (pp. 152165). Ft. Worth, TX: Harcourt Brace College Publishers.

Savin-Williams, R. C. \& Dube, E. M. (1998). Parental reactions to their child's disclosure of a gay/lesbian identity. Family Relations, 47, 7-13. doi:10.2307/584845

Savin-Williams, R. C. (2005). The new gay teenager. New York: Harvard Press. 
Savin-Williams, R. C. (2001). Mom, Dad. I'm gay. How families negotiate coming out. American Psychological Association: Washington, DC.

Savin-Williams, R. C. \& Dube, E. M. (1998). Parental reactions to their child's disclosure of a gay/lesbian identity. Family Relations, 47, 7-13.

Savin-Williams, R. C. \& Ream, G. L. (2003). Sex variations in the disclosure to parents of samesex attraction. Journal of Family Psychology, 17, 429-438. doi:10.1037/0893-3200.17.3. 429

Soliz, J. (2007). Communicative predictors of a shared family identity: Comparison of grandchildren's perceptions of family-of-origin grandparents and stepgrandparents. Journal of Family Communication, 7, 177-194. doi:10.1080/15267430701221636

Soliz, J. \& Giles, H. (2014). Relational and identity processes in communication a contextual and meta-analytical review of communication accommodation theory. In E. L. Cohen (Ed.) Communication Yearbook 38 (pp. 107-143). New York: Routledge.

Soliz, J., \& Harwood, J. (2003). Perceptions of communication in a family relationship and the reduction of intergroup prejudice. Journal of Applied Communication Research, 31, 320.

Soliz, J., Ribarsky, E., Harrigan, M. M., \& Tye-Williams, S. (2010). Perceptions of communication with gay and lesbian family members: Predictors of relational satisfaction and implications for outgroup attitudes. Communication Quarterly, 58, 77-95. doi:10.1080/01463370903538622

Soliz, J. \& Rittenour, C. E. (2012). Family as an intergroup arena. In H. Giles (Ed.), The Handbook of Intergroup Communication (pp. 331-343). New York: Routledge.

Spitzberg, B. H. (1983). Communication competence as knowledge, skill, and impression. Communication Education, 32, 323-329. 
Spitzberg, B. H. \& Cupach, W. R. (1984). Interpersonal communication competence. Beverly Hills, CA: Sage.

Spitzer, R. L., Kroenke, K., \& Williams, J. B. W. (2006). A brief measure for assessing generalized anxiety disorder. Journal of the American Medical Association, 10, 10921097 doi:10.1001/arcinte. 166.1092

Stavrakaki, C. \& Vargo, B. (1986). The relationship of anxiety and depression: A review of literature. The British Journal of Psychiatry, 149(1), 7-16. doi:10.1192/bjp.149.1.7

Svab, A. \& Kuhar, R. (2014). The transparent and family closets: Gay men and lesbians and their families of origin. Journal of GLBT Family Studies, 10, 15-35. doi:10.1080/1550428X.2014.857553

Szymanski, D. M., \& Gupta, A. (2009). Examining the relationship between multiple internalized oppressions and African American lesbian, gay, and bisexual persons' selfesteem and psychological distress. Journal of Counseling Psychology, 56, 110-118. doi:10.1037/a0013317

Szymanski, D. G. (2009). Examining potential moderators of the link between heterosexist events and gay and bisexual men's psychological distress. Journal of Counseling Psychology, 56, 142-151. doi:0.1037/0022-0167.56.1.142

Tremble, B., Schneider, M., \& Appathurai, C. (1989). Growing up gay or lesbian in a multicultural context. Journal of Homosexuality, 17(3-4), 253-268.

Tyler, T. R. (2015). Our story: The parent and LGBTQ child relational process. Journal of Gay \& Lesbian Social Services, 27, 17-45. doi:10.1080/10538720.2015.988313 
Ueno, K. (2005). Sexual orientation and psychological distress in adolescence: Examining interpersonal stressors and social support processes. Social Psychology Quarterly, 68, $258-277$.

Voci, A., \& Hewstone, M. (2003). Intergroup contact and prejudice toward immigrants in Italy: The mediational role of anxiety and the moderational role of group salience. Group Processes \& Intergroup Relations, 6, 37-54.

Warshak, R. A. (2001). Current controversies regarding parental alienation syndrome. American Journal of Forensic Psychology, 19, 29-60. Retrieved from https://www.fact.on.ca/Info/pas/warsha01.htm

Willoughby, B. L. B., Doty, N. D., \& Malik, N. M. (2010). Victimization, familial rejection, and outcomes of gay, lesbian, and bisexual young people: The role of negative GLB identity. Journal of GLBT Family Studies, 6, 403-424. doi:10.1080/1550428X.2010.511085

Willoughby, B. L. B., Malik, N. M, Lindahl, K. M. (2006). Parental reactions to their sons' sexual orientation disclosures: The roles of family cohesion, adaptability, and parenting style. Psychology of Men \& Masculinity, 7(1), 14-26. doi:10.1037/1524-9220.7.1.14

Woodford, M. R., Kulick, A., \& Atteberry, B. (2015). Protective factors, campus climate, and health outcomes among sexual minority college students. Journal of Diversity in Higher Education, 8, 73-87. doi:10.1037/a0038552

Woodford, M. R., Kulick, A., Sinco, B. R., \& Hong, J. S. (2014). Contemporary heterosexism on campus and psychological distress among LGBQ students: The mediating role of self acceptance. American Journal of Orthopsychiatry, 84, 519-529. doi:10.1037/ort0000015

Wright, K. B. (2000). Social support satisfaction, on-line communication apprehension, and perceived life stress within computer-mediated support groups. Communication Research 
Reports, 17, 139-147. doi:10.1080/08824090009388760

Zimman, L. (2009). 'The other kind of coming out': Transgender people and the coming out narrative genre. Gender and Language, 3(1), 53-80. doi:10.1558/genl.v3il.53 


\section{Appendix A}

\section{Informed Consent}

Title of Study: An Investigation of LGBTQ+ Adult Children's Parent-child communication: Exploring Communication Privacy Management and Communication Accommodation (IRB \#2011678)

Researcher: Maria Butauski, doctoral candidate in the Department of Communication at the University of Missouri - Columbia

Purpose: The goal of this research is to explore how LGBTQ+ adult children's communication with their parents relates to mental health outcomes, such as anxiety and depression, and parentchild relationship satisfaction.

Participants: To qualify for the study, you must be at least 18 years old, identify as LGBTQ+ (lesbian, gay, bisexual, transgender, queer, pansexual, nonbinary or gender-queer, asexual, aromantic, etc.) and be willing to voluntarily participate in research by completing an online survey about your parent-child communication.

Confidential: The survey is anonymous and participation is voluntary. You will not be asked to share any identifying information in your responses. You may skip questions at any time.

Risk: There is minimal risk involved in participating in this research. In other words, the risk involved in participating will not be greater than those ordinarily encountered in daily life. You may skip or not respond to any specific question or stop answering questions at any time. If you experience emotional distress, there is a Counseling Center at University of Missouri. Their phone number is 573-882-1682. If you have questions regarding your rights as a research participant, please call 573-882-9585.

Benefits: The results of this study will help scholars and society understand more about the dynamics of LGBTQ+ individuals' parent-child relationships and how their parent-child communication relates to important mental health outcomes.

Time: In total, participation should take approximately 20 to 30 minutes.

Contact: If you have any questions, please ask! You may contact the principal investigator, Maria Butauski at mcbvh8@mail.missouri,edu, or at 614-325-8720

By clicking "I have read and understand the information above and agree to participate in this study" you indicate that you have read and understand the information provided above and have decided to complete this survey for the purpose of voluntary research participation. *You may skip any questions you wish not to answer or feel uncomfortable answering. You may withdraw at any time, without prejudice, after agreeing to participate if you wish to discontinue the participation in this study. 


\section{Appendix B \\ Survey Items}

\section{Parents' Respect for Divergent Values}

Thinking about your communication with your (selected parent), please select the response that best describes your (selected parent)'s communication.

\section{Strongly Disagree 12345 Strongly Agree}

1. My (selected parent) is respectful of my opinions in our conversations.

2. In our interactions, my (selected parent) takes my views and opinions into account.

3. My (selected parent) is generally respectful of my beliefs when we talk about our opinions.

4. My (selected parent) is tolerant of my beliefs when we disagree.

\section{Parents' SGM Identity Support}

Thinking about your relationship with your (selected parent), please rate the degree to which you agree with the following statements.

\section{Strongly Disagree 12345 Strongly Agree}

1. I know my (selected parent) supports my LGBTQ+ identity.

2. My (selected parent) does not pressure me to conform to heteronormativity (i.e.,heterosexual and/or cisgender norms/expectations).

3. It is difficult to talk to my (selected parent) about topics related to my LGBTQ+ identity because my (selected parent) isn't fully supportive of it.*

4. My (selected parent) listens to me when I talk about topics related to my LGBTQ identity even though my (selected parent) doesn't fully support me identifying as LGBTQ.

* denotes reverse coded items.

Child-Parent Communication Apprehension

Thinking about your relationship with your (selected parent), please rate the degree to which you agree with the following statements.

\section{Strongly Disagree 12345 Strongly Agree}

1. I feel relaxed when talking with my (selected parent) about things that happened during the day.*

2. I have no fear in discussing problems with my (selected parent). ${ }^{*}$

3. I am comfortable in developing intimate conversations with my (selected parent).*

4. I look forward to talks with my (selected parent).* 
5. When in casual conversations with my (selected parent) I don't feel I have to guard what I say.*

6. I am afraid to come right out and tell my (selected parent) exactly what I mean.

7. I am so relaxed with my (selected parent) that I can really be an open communicator with $\operatorname{him} /$ her.*

8. I am tense when developing in-depth conversations with my (selected parent).

9. I feel strained when anticipating talks with my (selected parent).

10. Even in casual conversations with my (selected parent), I feel anxious and must guard what I say.

11. I have no fear telling my (selected parent) exactly how I feel.*

12. I have no anxiety about telling my (selected parent) my needs.*

* denotes reverse coded items.

GAD-7: A Brief Measure for Assessing Generalized Anxiety Disorder

Over the last 2 weeks, how often have you been bothered by the following problems? $(1=$ not at all, 2 = several days, $3=$ more than half the days, $4=$ nearly every day)

1. Feeling nervous, anxious, or on edge

2. Not being able to stop or control worrying

3. Worrying too much about different things

4. Trouble relaxing

5. Being so restless that it is hard to sit still

6. Becoming easily annoyed or irritable

7. Feeling afraid as if something awful might happen

The Patient Health Questionnaire (PHQ-9): Brief Depression Severity Measure

Over the last 2 weeks, how often have you been bothered by the following problems? $(1=$ not at all, $2=$ several days, $3=$ more than half the days, $4=$ nearly every day)

1. Little interest or pleasure in doing things

2. Feeling down, depressed, or hopeless

3. Trouble falling or staying asleep, or sleeping too much

4. Feeling tired or having little energy

5. Poor appetite or overeating

6. Feeling bad about yourself - or that you are a failure or have let yourself or your family down

7. Trouble concentrating on things, such as reading the newspaper or watching television

8. Moving or speaking so slowly that other people could have noticed? OR the oppositebeing so fidgety or restless that you have been moving around a lot more than usual

9. Thoughts that you would be better off dead or of hurting yourself in some way 


\section{VITA}

Maria Butauski was born in Cincinnati, Ohio on April 22, 1991. She graduated from Hilliard Darby High School in Hilliard, Ohio in 2009. Later that Fall, she started her undergraduate program at Xavier University in Cincinnati, Ohio and majored in Organizational Communication and Public Relations. Maria graduated with her bachelor's degree in May 2013 and moved to Northeast Ohio for her master's program at Kent State University, where she was advised by Drs. Mei-Chen Lin and Jeffrey Child. Maria then started her doctoral program at the University of Missouri in Fall 2015 as she was finishing her master's thesis. She completed her master's thesis in April 2016 and During her doctoral program, Maria was advised by Dr. Haley Horstman. Maria's work in the campus and local community during her time as a doctoral student ignited her passion for social justice and community engagement. The doctoral program built Maria's expertise in interpersonal and family communication and resilience-focused research. Three years after completing her master's thesis, Maria successfully defended her dissertation in April 2019 and received her Ph.D. in Communication in May 2019. 